1

10 Correspondence:

11 Matthew D. Welch

12 Department of Molecular and Cell Biology

13301 Weill Hall

14 University of California, Berkeley

15 Berkeley, CA 94720-3200

16

\title{
A patatin-like phospholipase mediates Rickettsia parkeri escape from host membranes
}

Gina M. Borgo ${ }^{1,2}$, Thomas P. Burke ${ }^{2}$, Cuong J. Tran ${ }^{1,2}$, Nicholas T. N. Lo ${ }^{1}$, Patrik Engström², Matthew D. Welch ${ }^{2}$ University of California, Berkeley, Berkeley, CA, USA 


\section{Abstract:}

18 Spotted fever group Rickettsia species are arthropod-borne obligate intracellular

19 bacteria that can cause mild to severe human disease. These bacteria invade host

20 cells, replicate in the cell cytosol, and then spread from cell to cell. To access the host

21 cytosol and avoid detection by immune surveillance mechanisms, these pathogens

22 must have evolved efficient ways to escape membrane-bound vacuoles. Although

23 Rickettsia are predicted to express factors that disrupt host membranes, little is known

24 about how and when these proteins function during infection. Here, we investigated the

25 role of a Rickettsia patatin-like phospholipase A2 enzyme (Pat1) during host cell

26 infection by characterizing a Rickettsia parkeri mutant with a transposon insertion in the

27 pat1 gene. We show that Pat1 is important for infection in a mouse model and in host

28 cells. We further show that Pat1 is critical for efficiently escaping from the single and

29 double membrane-bound vacuoles into the host cytosol, and for avoiding host galectins

30 that mark damaged membranes. In the host cytosol, Pat1 is important for avoiding host

31 polyubiquitin, preventing recruitment of autophagy receptor p62, and promoting actin-

32 based motility and cell-cell spread. Our results show that Pat1 plays critical roles in

33 escaping host membranes and promoting cell-cell spread during $R$. parkeri infection and

34 suggest diverse roles for patatin-like phospholipases in facilitating microbial infection. 


\section{Importance:}

39 Spotted fever group Rickettsia are bacteria that reside in ticks and can be transmitted to

40 mammalian hosts, including humans. Severe disease is characterized by high fever,

41 headache, and rash, and results in occasional mortality despite available treatment.

42 Rickettsia interact with host cell membranes while invading cells, escaping into the

43 cytosol, and evading cellular defenses. Bacterial phospholipase enzymes have been

44 proposed as critical factors for targeting host cell membranes, however the specific

45 roles of rickettsial phospholipases are not well defined. We investigated the contribution

46 of one conserved patatin-like phospholipase, Pat1, in Rickettsia parkeri. We observed

47 that Pat1 is important for virulence in an animal model. Moreover, Pat1 plays critical

48 roles in host cells by facilitating access to the cell cytosol, inhibiting detection by host

49 defense pathways, and promoting cell-cell spread. Our study indicates that Pat1

50 performs several critical functions, suggesting a broad role for phospholipases

51 throughout the Rickettsia lifecycle. 


\section{Introduction}

Spotted fever group (SFG) Rickettsia species are Gram-negative, obligate

54 intracellular bacteria that infect tick vectors and can be transmitted by tick bites to

55 vertebrate hosts (1). SFG Rickettsia that can cause disease in humans include $R$.

56 rickettsii, the causative agent of Rocky Mountain spotted fever, a disease characterized

57 by high fever, neurological symptoms, organ failure, and possible fatality if left untreated

58 (2, 3). Disease-causing SFG Rickettsia also include species such as $R$. parkeri, which

59 causes milder eschar-associated rickettsiosis characterized by fever and a skin lesion

60 (eschar) at the site of the tick bite, but is not documented to cause fatality $(2,4,5)$.

61 Because $R$. parkeri can be studied under biosafety level 2 (BSL2) conditions, it is

62 emerging as a model for understanding the molecular determinants of SFG Rickettsia

63 pathogenicity.

R. parkeri targets macrophages (4-8) as well as endothelial cells $(6,7,9)$ during

65 infection in humans and animal models. Upon invasion of host cells, bacteria escape

66 from the primary vacuole into the cytosol, where they replicate $(10,11)$. Bacteria then

67 initiate actin-based motility and move to the plasma membrane, where they enter into

68 protrusions that are engulfed into neighboring cells (12). This necessitates another

69 escape event from a double-membrane secondary vacuole into the cytosol, completing

70 the intracellular life cycle $(10,11)$. Other bacteria with a similar life cycle utilize pore-

71 forming proteins and phospholipases to escape from the primary and/or secondary

72 vacuole. For example, Shigella flexneri uses the IpaB-IpaC translocon to form pores that

73 facilitate membrane rupture (13-18). Listeria monocytogenes utilizes the cholesterol- 
74 dependent cytolysin listeriolysin O (LLO) (19-22) and two phospholipase C enzymes,

75 PlcA and PlcB, to escape from primary and secondary vacuoles $(19,23-27)$. It is likely

76 that Rickettsia also utilizes at least one protein that can directly disrupt the vacuolar

77 membrane to mediate escape.

SFG Rickettsia genomes encode two types of phospholipase enzymes,

79 phospholipase D (PLD) and up to two patatin-like phospholipase A2 (PLA2) enzymes

(Pat1 and Pat2) $(28,29)$. PLD is dispensable for vacuolar escape, as a pld mutant in $R$.

81 prowazekii showed no delay in escape (30), even though exogenous PLD expression in

82 Salmonella enterica was sufficient to facilitate escape (31). In contrast, evidence suggests

83 a possible role for PLA2 enzymes in escape. For example, PLA2 activity from $R$.

84 prowazekii was demonstrated to target host phospholipids throughout infection $(32,33)$.

85 Furthermore, pretreatment of bacteria with either a PLA2 inhibitor, or anti-Pat1 or anti-

86 Pat2 antibodies, reduced plaque number for both $R$. rickettsii (34-36) and $R$. typhi (28,

87 37), and increased colocalization of $R$. typhi with the lysosomal marker LAMP-1 (37). This

88 suggests that Pat1 and Pat2 are important for infection and avoidance of trafficking to the

89 lysosome. Nevertheless, the precise role of PLA2 enzymes in rickettsial vacuolar escape

90 has remained unclear.

91 Phospholipase activity and escape from the vacuole may also be important to

92 enable downstream life cycle events, such as actin-based motility, which requires access

93 to actin in the host cell cytosol. Another is avoidance of anti-bacterial autophagy (also

94 called xenophagy). Autophagy can be initiated via polyubiquitination of cytosolic bacteria

95 (38-40) and subsequent recruitment of autophagy receptors (41) such as 
96 p62/Sequestome 1 (SQSTM1) (hereafter referred to as p62) (42-44) and NDP52 (nuclear

97 dot protein 52 (NDP52)/calcium-binding and coiled-coil domain 2 (CALCOCO2))

98 (hereafter referred to as NDP52) (42, 45, 46). Autophagy receptors recognize

99 polyubiquitinated bacteria and interact with microtubule-associated protein 1A/1B-light

100 chain 3 (LC3), which marks nascent and mature autophagosomal membranes that can

101 enclose bacteria and deliver them to the lysosome $(38,47,48)$. Bacterial phospholipases

102 may facilitate autophagy avoidance through manipulation of phospholipids needed for

103 autophagosome formation, such as with L. monocytogenes PlcA targeting of

104 phosphatidylinositol 3-phosphate (PI(3)P) to block LC3 lipidation $(49,50)$.

105

Autophagy can also be initiated by membrane damage to the bacteria-containing

106 vacuole, which exposes glycans internalized from the host cell surface that are

107 recognized by host cytosolic glycan-binding galectin (Gal) proteins (51). Gal3 and Gal8

108 can target damaged vacuolar compartments during infection with L. monocytogenes (52,

$10953)$ and $S$. flexneri $(52,54,55)$, as well as during infection with bacteria that typically

110 reside in membrane-bound compartments such as Legionella pneumophila (56), S.

111 enterica (52, 55), Coxiella burnetti (57), and Mycobacterium tuberculosis (58).

112 Importantly, membrane remnants marked by Gal3 or Gal8 colocalize with polyubiquitin

$113(54,58,59)$, autophagy receptors p62 $(54,58)$ and NDP52 $(55,57)$, and LC3 $(54,55,57$,

114 58). Nevertheless, it remains unknown if rickettsial phospholipases are important to evade

115 autophagy.

To better understand the role of PLA2 enzymes during SFG Rickettsia infection,

117 we characterized a $R$. parkeri mutant with a transposon insertion in the single PLA2- 
118

119

120

121

122

123

124

125

126

127

128

129

130

131

132

133

134

135

136

137

138

encoding gene pat1. We found that Pat1 is critical throughout infection for escaping host membranes, avoiding targeting by autophagy, and spreading to neighboring cells. These results suggest that Pat1 is a key bacterial factor involved in interacting with host membranes and avoiding detection in host cells.

\section{Results:}

\section{Pat1 is important for infection of host cells and contributes to virulence in mice}

To determine the role of Pat1 during infection, we used a $R$. parkeri mutant with a transposon insertion in the pat1 gene (pat1::Tn) that was previously isolated in a screen for mutants with reduced plaque size (60). We complemented the pat1::Tn mutation by generating a strain (pat1::Tn pat1 $1^{+}$) that contains a second transposon encoding full length pat1 plus the intergenic regions immediately 5' and 3' to the gene (predicted to contain the native promoter and terminator) (Fig. 1A). Using an antibody that recognizes R. parkeri Pat1 by western blotting, we observed a band at the predicted molecular weight of $55 \mathrm{kD}$ for Pat1 in WT bacteria, no corresponding band in the pat1::Tn mutant, and a restoration of the band in the pat1::Tn pat1+-complemented mutant (Fig. 1B). The absence of detectable Pat1 protein in the mutant suggests it is a null mutant. Because the pat1::Tn mutant was initially identified based on its small-plaque phenotype, we next compared plaque area for WT, mutant, and complemented mutant strains. In comparison with WT, the pat1::Tn mutant showed significantly smaller plaques, and plaque area was 
139

140

141

142

143

144

145

146

147

148

149

150

151

152

153

154

155

156

157 Pat1 promotes efficient escape from the vacuole post-invasion

158

159

160 reduction in plaque area was caused by loss of pat1. disruption of pat1 does not interfere with intracellular growth in these cell lines. indicate that Pat1 is an important virulence factor.

rescued in the complemented mutant (Fig. 1C, D). This demonstrates that the observed

To further determine if Pat1 plays a role in bacterial replication, growth curves measuring PFU were performed in human microvascular endothelial cells (HMECs). There were no differences in bacterial replication kinetics for WT, pat1::Tn and pat1::Tn pat $1^{+}$-complemented strains in HMECs (Fig. 1E). These data indicate that the transposon

We next examined the contribution of Pat1 to virulence in vivo using mice lacking the receptors for both IFN-I (Ifnar1) or IFN- $\gamma$ (Ifngr1) (Ifnar1 ${ }^{-/-}$;fngr $1^{-/-}$double knock out mice), which succumb to infection with WT $R$. parkeri and can be used to investigate the importance of bacterial genes to virulence $(8,61)$. Mice infected intravenously (i.v.) with $5 \times 10^{6}$ PFU WT bacteria showed a rapid drop in temperature and body weight following infection and did not survive past day 8 (Fig 1F, G, H). In contrast, mice infected i.v. with the pat $1:: T n$ mutant maintained a steady temperature following infection, showed an initial drop in weight that stabilized around 2 weeks post infection before increasing, and the majority survived until the end of the experiment (day 40) (Fig. 1F, G, H). These results

Because R. typhi Pat1 and Pat2 had previously been implicated in avoidance of trafficking to lysosomes (37), we sought to determine if the $R$. parkeri pat1::Tn mutant was impaired in its ability to escape from the primary vacuole during infection. To evaluate 
161 the role of Pat1 in vacuolar escape, we used transmission electron microscopy (TEM) to

162 investigate whether host membranes surrounded intracellular bacteria $1 \mathrm{~h}$ post infection

163 (hpi) in HMECs. This time point was chosen because prior studies reported escape from

164 the vacuole by 30 min post infection (mpi) for $R$. typhi (37), R. prowazekii (30), and $R$ 165 conorii (62). At this timepoint, significantly more WT bacteria were found free in the cytosol 166 (74\%) compared with the pat1::Tn mutant (38\%) (Fig. 2A, B). Moreover, significantly

167 fewer WT bacteria were found within membranes (25\% in single membranes, $1 \%$ in 168 double membranes) in comparison with the pat1::Tn mutant (50\% in single membranes, $16912 \%$ within double membranes). Differences in vacuolar localization were not due to 170 differences in invasion of host cells, as both WT and the pat1::Tn mutant entered cells 171 with similar kinetics (Fig. 2C). These results suggest that Pat1 facilitates escape from 172 membranes following invasion.

We further hypothesized that the increased localization of the pat1::Tn mutant

174 within membranes impaired access to the cytosol, particularly to the pool of actin, 175 interfering with actin-based motility. To test this hypothesis, we quantified the number of 176 bacteria with actin tails at $30 \mathrm{mpi}$ and $1 \mathrm{hpi}$. Approximately $3-4 \%$ of WT bacteria were 177 associated with actin tails, in keeping with previous reports $(63,64)$. The frequency of 178 pat1::Tn mutant association with actin tails was half that of WT at both time points (Fig. 179 2D). These results suggest that failure of the pat $1:: T n$ mutant to escape from the vacuole 180 leads to reduction in actin-based motility. To confirm that the reduced frequency of actin181 based motility resulted from bacteria being trapped within membranes, we used hypotonic 182 shock (alternating treatment with hypertonic and then hypotonic solutions) to lyse primary 
183 vacuoles $(65,66)$ and more efficiently deliver bacteria to the cytosol. When cells infected

184 with WT bacteria were subjected to hypotonic shock at $5 \mathrm{mpi}$, there was no significant

185 increase in the percentage of bacteria with actin tails at $30 \mathrm{mpi}$, suggesting that WT

186 bacteria optimally access the cytosol following invasion (Fig. 2E). In contrast, hypotonic

187 shock significantly increased the percentage of pat1::Tn mutant bacteria with actin tails.

188 These results confirm that reduced frequency of actin-based motility in the pat1::tn mutant

189 is due to entrapment in the primary vacuole.

190

191 Pat1 contributes to autophagy avoidance

The presence of a marked fraction (12\%) of pat1::Tn mutant bacteria in double-

193 membrane compartments at $1 \mathrm{hpi}$ could not be explained by failure to escape from the

194 vacuole, suggesting the possibility that bacteria were targeted by host cell autophagy.

195 Because an initial step of anti-bacterial autophagy is recognition and ubiquitylation of the

196 bacterial surface (40), we first tested for bacterial association with polyubiquitin in infected

197 HMECs at 0-2 hpi. Whereas fewer than 2\% of WT bacteria were polyubiquitin-positive

198 from 0-2 hpi, the percentage of polyubiquitin-positive pat1::Tn mutant bacteria was

199 significantly higher and increased (from about $6 \%$ at $0 \mathrm{hpi}$ to about $16 \%$ at $1 \mathrm{hpi}$ ), before

200 falling slightly (Fig. 3A, B). Complementation of the pat1::Tn mutant reduced the percent

201 of polyubiquitin-positive bacteria to levels seen with WT (Fig. 3C). This suggests that Pat1

202 reduces recognition of bacteria by the host ubiquitylation machinery.

203

To further examine whether bacteria were targeted by the autophagy machinery,

204 we examined the recruitment of autophagy receptors p62 and NDP52, as well as LC3 at 
$2051 \mathrm{hpi}$, the time point with the most polyubiquitin-positive bacteria. Compared with WT

206 (fewer than $2 \%$ stained with these markers), markedly more of the pat $1:$ Tn mutant were

207 positive for p62 (10\%) and NDP52 (6\%) (Fig. 4A, B, C). Moreover, more of the pat1::Tn

208 mutant bacteria colocalized with LC3 at 1 and 2 hpi (Fig. 4D, E). Interestingly, the

209 increased recruitment of LC3 to the pat1::tn mutant preceded increased colocalization of

210 the mutant with LAMP-1, a marker for late endosomal and lysosomal compartments (Fig.

211 S1A, B). These results suggest that Pat1 is important for counteracting the recruitment

212 of autophagy receptors and targeting to autophagosomes and lysosomes.

Because previous studies suggested that Pat1 is secreted into the host cell (37),

214 we also sought to further ascertain whether Pat1 was counteracting ubiquitylation and

215 targeting by the autophagy machinery by acting locally on the bacterium producing the

216 protein, and/or by acting at a distance on other bacteria. To test this, we co-infected

217 HMECs with WT bacteria expressing 2xTagBFP and with pat1::Tn mutant bacteria, and

218 quantified colocalization of pat1::Tn bacteria with polyubiquitin, NDP52, and p62. The

219 pat1::Tn mutant exhibited significantly reduced colocalization with polyubiquitin and p62

220 (but not NDP52) in co-infected cells compared with cells infected with the pat1::Tn mutant

221 only (Fig. 4F). These results suggest that Pat1 is secreted and can function at a distance

222 to reduce bacterial targeting with polyubiquitin and p62. 
It remained unclear whether polyubiquitin and the autophagy machinery were

227

228

229

230

231

232

233

234

235

236

237

238

239

240

241

242

243

244

245

246

247 associated with bacteria enclosed in damaged vacuolar membranes or those free in the cytosol. To determine whether polyubiquitin, NDP52, and p62 were present at damaged vacuoles at $1 \mathrm{hpi}$, we quantified the percentage of bacteria staining for polyubiquitin, NDP52, or p62, in cells transiently expressing Gal3-mCherry or Gal8-mCherry to mark damaged membranes $(52,55)$ (Fig. 5A, B). A small fraction $(0.5 \%)$ of WT bacteria colocalized with Gal3-mCherry or Gal8-mCherry, whereas significantly more pat1::tn mutant bacteria colocalized with Gal3-mCherry or Gal8-mCherry ( 2.5\%) (Fig. 5C, D). A significantly higher fraction of the pat1::Tn mutant bacteria that stained for NDP52 also colocalized with either Gal protein ( $50 \%)$ (Fig. 5E). Some pat1::Tn mutant bacteria that stained for p62 also colocalized with Gal3-mCherry ( 5\%) or Gal8-mCherry ( 10\%) (Fig. 5E). We rarely observed colocalization of the pat1::Tn mutant bacteria with both polyubiquitin and either Gal protein (Fig. 5E). Interestingly, although the pat1::Tn mutant was more frequently associated with Gal3-mCherry or Gal8-mCherry, in pat1::Tn mutantinfected cells we observed fewer clusters of Gal3-mCherry (Fig. S2A, C) or Gal8-mCherry (Fig. S2B, D) not associated with bacteria, consistent with reduced overall membrane damage compared with cells infected with WT bacteria.

To test whether NDP52 associated with bacteria or damaged membranes, we performed the hypotonic shock treatment (Fig. 2E) to release bacteria from host vacuoles. Cells infected with WT and pat1::Tn bacteria were subjected to hypotonic shock treatment at $5 \mathrm{mpi}$, and then at $30 \mathrm{mpi}$, we quantified the number of bacteria that colocalized with NDP52. Hypotonic shock significantly reduced the percent colocalization 
248 of the pat1::Tn with NDP52 (from $\sim 6 \%$ in untreated cells to $\sim 1 \%$ in treated cells), while

249 fewer than $1 \%$ of WT bacteria colocalized with NDP52 regardless of treatment (Fig. $\mathbf{5 F}$ ).

250 Together, these results support the conclusion that Pat1 promotes efficient escape from

251 vacuolar membranes and enables avoidance of targeting by Gal3, Gal8, and NDP52.

252

253 Pat1 facilitates actin-based motility and spread into neighboring cells late in 254 infection

255

Although Pat1 is dispensable for bacterial replication kinetics, it promotes plaque

256 formation, suggesting that Pat1 may function in cell-cell spread. To initially assess if Pat1

257 is important for spread, we used an infectious focus assay, in which the number of

258 infected host cells per focus of infection was quantified at $28 \mathrm{hpi}$ to measure spread

259 efficiency (67). Compared with WT bacteria ( 4.5 cells per focus), the pat1::Tn mutant

260 infected significantly fewer cells ( $\sim 3.5$ cells per focus) (Fig. 6A, B). This suggested that

261 Pat1 is important for spread. To further assess cell-cell spread, we carried out a "mixed

262 cell" assay (67) in which "primary" A549 cells stably expressing the TagRFP-T-farnesyl

263 plasma-membrane marker (A549-TRTF) were infected for $1 \mathrm{~h}$, detached from the plate,

264 and mixed with unlabeled "secondary" A549 cells (Fig. 6C, D). The percent of bacteria in

265 the primary A549-TRTF cell and secondary cell were quantified at $32 \mathrm{hpi}$. We observed

266 that $50 \%$ of WT bacteria were found in primary cells and $50 \%$ had spread into secondary

267 cells. In contrast, $\sim 85 \%$ of pat1::Tn mutant bacteria remained in primary cells and only

$268 \sim 15 \%$ had spread to secondary cells (Fig. 6C, E). This confirms that Pat1 is important for

269 cell-cell spread. 
Because our data indicated that Pat1 facilitates cell-cell spread, we further

271 investigated whether Pat1 influences actin-based motility, which is known to contribute to

272 spread $(63,64)$. We found that the pat1::Tn mutant formed significantly fewer actin tails

273 compared to WT bacteria at $24 \mathrm{hpi}$ and $48 \mathrm{hpi} \mathrm{(Fig.} \mathrm{6F,} \mathrm{G),} \mathrm{suggesting} \mathrm{fewer} \mathrm{bacteria}$

274 initiated actin-based motility. Complementation of the pat1::Tn (pat1::Tn pat1+) mutant

275 restored the frequency of actin tail formation to WT levels (Fig. S3A, B). In the mixed cell

276 assay, which distinguishes between primary and secondary cells, $6 \%$ of WT bacteria in

277 the primary cell assembled actin, mostly as actin tails but also as "clouds" of actin

278 surrounding the bacteria, compared with $\sim 1 \%$ of pat1::Tn mutant bacteria (Fig. S3C).

279 Differences between WT and pat1::Tn bacteria in the secondary cell could not be

280 discerned. The observed differences between WT and the pat1::Tn mutant were not due

281 to differences in the localization of the R. parkeri protein Sca2, which is important for

282 actin-based motility and cell-cell spread $(64,68)$ (Fig. S3D). Taken together, these results

283 suggest that Pat1 is important for the frequency of bacterial actin-based motility, and

284 hence bacterial spread to neighboring cells.

285

286 Pat1 is important for avoiding double membranes during cell-cell spread

Because Pat1 played an important role escaping the primary vacuole following

288 invasion, we hypothesized that it also played a role in escaping the secondary vacuole

289 following cell-cell spread. To test this, we imaged infected HMECs by TEM at $48 \mathrm{hpi}$ and

290 quantified the percent of intracellular bacteria free in the cytosol or within membranes.

291 Significantly more pat1::Tn mutant bacteria were surrounded by double membranes 
292 ( 60\%) in comparison with WT bacteria ( 25\%) (Fig. 7A, B). The double membranes we

293 observed were often discontinuous, with the mutant remaining mostly enclosed and WT

294 bacteria having very few surrounding membrane fragments. This suggests that Pat1 plays

295 a role in escaping from membranes later in infection.

We next sought to further distinguish whether bacteria surrounded by double

297 membranes were in secondary vacuoles that result from cell-cell spread, or other double-

298 membrane structures involved in autophagy. To determine targeting by autophagy at 48

299 hpi, we assessed whether bacteria colocalized with polyubiquitin, p62 or NDP52 at 48

300 hpi. Significantly more of the pat1::Tn mutant colocalized with p62 and NDP52 than WT,

301 although the overall percentages were low in all cases (Fig. 7C). Moreover, the

302 percentage of bacteria that colocalized with these markers was lower than at $1 \mathrm{hpi}$

303 (compare with Fig. 3B, 4C). Interestingly, polyubiquitin labeling was not significantly

304 different between WT and pat1::Tn mutant bacteria, suggesting the observed differences

305 in colocalization with autophagy receptors p62 and NDP52 between WT and the pat1::Tn

306 mutant were not mediated by differences in polyubiquitin recruitment. These data suggest

307 that a minor fraction of double membranes observed by TEM at $48 \mathrm{hpi}$ are

308 autophagosomes and Pat1 plays a minor role in autophagy avoidance at late timepoints.

To determine whether there instead were differences in escape from secondary

310 vacuole, we used the mixed cell assay described above, in which infected primary cells

311 stably expressing TagRFP-T-farnesyl were infected for $1 \mathrm{~h}$ and then mixed with

312 uninfected and unlabeled secondary cells (Fig. 6C, D). Fewer than $1 \%$ of WT bacteria

313 that spread from primary into secondary cells were colocalized with the plasma 
314 membrane marker from the primary cell (Fig. 7D), suggesting that these bacteria had

315 escaped the secondary vacuole. In contrast, of the pat $1:$ Tn mutant bacteria that spread

316 into secondary cells, $\sim 12 \%$ colocalized with the plasma membrane marker from the

317 primary cell. These results suggest that a significant fraction of double-membrane

318 structures seen in the TEM images are secondary vacuoles and confirm that Pat1 is

319 important for escaping from these vacuoles.

322 Discussion

323 The ability of Rickettsia species to escape the vacuole and avoid host membranes

324 is a critical facet of their life cycle. Here, we demonstrate that the $R$. parkeri patatin-like

325 phospholipase, Pat1, is important for virulence in a mouse model of infection. At the

326 cellular level, we find that Pat1 enables bacterial escape from host membranes

327 throughout infection. Pat1 mediates efficient exit from primary vacuoles following

328 invasion, helping $R$. parkeri avoid detection by host galectins and autophagy adaptor

329 NDP52. Pat1 further enables cytosolic bacteria to avoid recruitment of polyubiquitin and

330 autophagy adaptor p62. As infection progresses, Pat1 facilitates spread into neighboring

331 cells and escape from the secondary vacuole. Altogether, these data suggest Pat1 is

332 important at multiple steps of the Rickettsia life cycle that involve manipulating host

333 membranes.

Our work shows that Pat1 is important for virulence upon i.v. infection in a mouse

335 model that succumbs to R. parkeri infection $(8,61)$. This is consistent with other bacterial 
336 factors involved in vacuolar escape being important virulence factors in animal models of

337 disease. For example, L. monocytogenes mutants lacking LLO are avirulent upon i.v.

338 infection in a mouse model and single L. monocytogenes PLC mutants are also

339 diminished in virulence (27). Our data suggests that Pat1 plays an important role in $R$.

340 parkeri pathogenesis.

Using TEM and confocal microscopy, we found that Pat1 mediates escape from

342 both single and double membrane compartments in host cells. At early time points,

343 pat1::Tn mutant bacteria were more frequently surrounded by single membranes

344 following invasion, likely to be primary vacuoles derived from the host cell plasma

345 membrane. Consistent with a failure to fully escape the primary vacuole, the pat1::Tn

346 mutant also showed a reduced frequency of actin-based motility and increased trafficking

347 to LAMP-1-positive compartments. We also found the pat1::Tn mutant had increased

348 localization to double membrane structures at later time points when bacteria are

349 spreading to neighboring cells. These structures are likely to be secondary vacuoles, as

350 only a small portion colocalized with autophagy receptors p62 or NDP52. Pat1 was

351 previously suggested as a candidate for escape from the vacuole due to its phospholipase

352 activity $(28,37)$ and the observation that $R$. typhi pre-treated with anti-Pat1 antibody

353 (which could block surface-associated by not secreted Pat1) caused increased

354 colocalization with LAMP-1 (37). Our results provide genetic confirmation of this role.

355 Several other bacterial phospholipases mediate membrane rupture (69), including $L$.

356 monocytogenes PLCs $(19,26,27,69)$, Clostridium perfringens alpha-toxin (PLC) (69-

357 71), and Psuedomonas aeruginosa ExoU (69, 72). Similarly, lecithin:cholesterol 
358

359

360

361

362

363

364

365

366

367

368

369

370

371

372

373

374

375

376

377

379

378 phosphatidylinositol 3-kinase, was recently reported to manipulate early trafficking events

acyltransferase (LCAT) enzymes from pathogenic protists, including Plasmodium berghei phospholipase (PbPL) $(73,74)$ and Toxoplasma gondii TgLCAT (75), have PLA2 and acyl transferase activity that facilitate breakdown of the parasitophorous vacuole. Phospholipases are also used by nonenveloped viruses to breech the endosome (76), including parvovirus capsid protein VP1 which has PLA2 activity (77), and host PLA2 group XVI which is recruited by picornaviruses to endosomes for genome translocation (78). Thus, the role of Pat1 in vacuolar breakdown and escape is similar to functions of phospholipases in other intracellular pathogens.

Despite its importance in escaping from primary and secondary vacuoles, Pat1 is not important for growth in the cell line we tested, suggesting that other $R$. parkeri proteins help rupture vacuolar membranes and gain access to nutrients in the cytosol. Consistent with this notion, the pat1::Tn mutant colocalizes more frequently with damaged membranes marked by Gal3 and Gal8. Pat1 must therefore share functional redundancy with other proteins that also function in escape. This is similar to the redundancy between L. monocytogenes PLC enzymes, which also have overlapping roles in escape, with double mutants deficient in both PlcA and PlcB showing more severe defects in escape $(19,26,27)$ and growth $(27,49)$ than single mutants. Other Rickettsia factor(s) involved in escape may include TlyC, a putative hemolysin $(31,79)$, which could function analogously to LLO. Pat2, a second PLP, may also have an overlapping role with Pat1 in species like $R$. typhi $(28,37)$. In addition to the membranolytic proteins, Risk-1, a 379 important for invasion, vacuolar escape, and autophagy (80). Factors such as these are 
380

381

382

383

384

385

386

387

388

389

390

391

392

393

394

395

396

397

398

399 400

401

likely to function with Pat1 to allow complete escape from vacuolar membranes into the cytosol.

A key role for Pat1 in promoting efficient escape from damaged host membrane remnants is to enable subsequent avoidance of targeting of these membranes by Gal proteins and the autophagy machinery. Consistent with this, we observed that the pat1::Tn mutant colocalizes more frequently with Gal3 or Gal8 and the autophagy receptor NDP52. Interestingly, Gal3, but not Gal8, has been found to promote $L$. monocytogenes replication during infection by suppressing autophagy (53). During Group A Streptococcus infection, Gal3 has also been shown to prevent recruitment of Gal8 and parkin, which themselves play anti-bacterial roles (81). Whether differential recruitment of Gal3 and Gal8 leads to different outcomes during Rickettsia infection remains unknown.

We found that Pat1 plays a role in avoiding targeting by autophagy for bacteria that are not associated with damaged membranes. In support of this notion, the pat1::Tn mutant was subject to polyubiquitylation and p62 recruitment without co-recruitment of Gal proteins. Pat1 may thus augment other rickettsial autophagy-avoidance mechanisms, which include lysine methylation of $\mathrm{OmpB}$ and $\mathrm{OmpB}-$ mediated shielding of bacterial surface from polyubiquitylation $(82,83)$. In this role, Pat1 might function in a similar manner to PlcA from L. monocytogenes, which reduces $\mathrm{PI}(3) \mathrm{P}$ levels to block autophagosome formation and stall autophagy $(49,50)$. Both PlcA/B and Pat1 are secreted and can act at a distance, as it was previously shown that a $p / c A / B$ mutant can be rescued by co-infection with by WT L. monocytogenes (50), and we also observed 
402

403

404

405

406

407

408

409

410

411

412

413

414

415

416

417

418

419

420

421 intracellular life cycle in escaping from membranes, avoiding autophagy, and enabling

422 cell-cell spread. Whether Pat1 also performs other functions during infection remains

423 unknown. For example, secreted Pat1 could contribute to the release of bioactive lipids

rescue of a $R$. parkeri pat1::Tn mutant by co-infection with WT bacteria. Thus, secreted Pat1 might also target early and/or regulatory aspects of autophagy.

We further found that Pat1 is important for cell-cell spread, including in late actinbased motility and escape from the secondary vacuole (the latter is discussed above). The pat1::Tn mutant formed fewer actin tails and exhibited reduced spread into neighboring cells when compared with WT, consistent with the known role for motility in cell-cell spread of SFG Rickettsia $(63,64,68)$. One key contribution of Pat1 to actin-based motility is to mediate escape from the vacuole, allowing recruitment of the host actin machinery to the surface of the bacteria. However, it remains possible that Pat1 targeting of phosphoinositides (PIs) might also affect actin-based motility, as Pls influence the activity of actin-binding proteins (84-86). Moreover, Pat1 targeting of Pls at the plasma membrane could contribute to protrusion dynamics during cell-cell spread. PIs are implicated in the recruitment and function of the endocytic machinery (87-90). In turn, endocytic pathways have been shown to mediate protrusion engulfment for $L$. monocytogenes and $S$. flexneri $(87,88)$. Pat1-mediated local membrane damage might also promote spread, as L. monocytogenes LLO-mediated membrane damage in the protrusion has been shown to enable exploitation of efferocytosis for spread (89). Thus, Pat1 may play multiple roles in cell-cell spread.

Our data demonstrate that Pat1 plays important roles throughout the $R$. parkeri 
424 such as eicosanoids derived from arachidonic acid. Eicosanoid synthesis can impact

425 immunity, inflammation, and vascular function (90-92), and thus represents an

426 underexplored process that may be influenced by Rickettsia infection and disease.

427 Membranes are critical hubs of signaling and protein-protein interactions and R. parkeri,

428 like other intracellular pathogens, has likely evolved diverse ways of manipulating

429 membranes. Further studies of Pat1 function will elucidate how PLA2 enzymes facilitate

430 microbial adaptation to host cells and could reveal previously unappreciated strategies of

431 membrane manipulation by bacterial pathogens.

$434 \quad$ Materials and methods

\section{Mammalian cell lines}

Mammalian cell lines were obtained from the UC Berkeley Cell Culture Facility and

437 grown at $37^{\circ} \mathrm{C}$ with $5 \% \mathrm{CO}_{2}$. Vero cells (African green monkey kidney epithelial cells,

438 RRID:CVCL_0059) were grown in Vero media (DMEM with high glucose (4.5 g/L; Gibco,

439 catalog number 11965-092) and 2\% FBS (GemCell, 100500) for culturing or 5\% FBS for

440 plaque assays (described below)). A549 cells (human lung epithelial cells,

441 RRID:CVCL_0023) were grown in A549 media (DMEM (Gibco, 11965-092) with high

442 glucose (4.5 g/L) and 10\% FBS (ATLAS, F-0500-A)). A549 cells stability expressing a

443 farnesyl tagged TagRFP-T (A549-TRTF) to mark the plasma membrane were described

444 previously (67) and were also maintained in A549 media. HMEC-1 cells (human

445 microvascular endothelial cells RRID:CVCL_0307) were grown in HMEC media (MCDB

446131 media (Sigma, M8537) supplemented with 10\% FBS (HyClone, SH30088), 10 mM 
447 L-glutamine (Sigma, M8537), $10 \mathrm{ng} / \mathrm{ml}$ epidermal growth factor (Corning, 354001), 1 $448 \mathrm{ug} / \mathrm{mL}$ hydrocortisone (Spectrum Chemical, CO137), and $1.18 \mathrm{mg} / \mathrm{mL}$ sodium 449 bicarbonate).

450

451 Plasmid construction

452 For complementation of pat1::Tn pat1 + mutant, we constructed a pMW1650-Spec-

453 pat1 complementation plasmid. The plasmid pMW1650-Spec was derived from 454 pMW1650 (93) by deleting the gene encoding GFP and replacing the gene conferring 455 resistance to rifampicin with the aadA gene from $E$. coli to confer resistance to 456 spectinomycin (94). Nucleotides 901,999-903,853 from $R$. parkeri genomic DNA were 457 then amplified by PCR and inserted into pMW1650-Spec at the single Pstl site. Primers 458 used to amplify this region

459 ATTGCGACACGTACTCTGCAGATCTCATACCATCATAGTTATAATATTAGC-3' and 5'460 AGAGGATCCCCATGGCTGCAGACACAGGTGTCGTCATTGTGA-3') contained 15-bp

461 overhang with homology to the plasmid for InFusion (Takara Bio, 638947) cloning and 462 retained the Pst1 site. The amplified sequence contained a predicted promoter 5 ' to the 463 pat1 coding sequence (determined using SoftBerry, BPROM prediction of bacterial 464 promoters;

465 http://www.softberry.com/berry.phtml?topic=bprom\&group=programs\&subgroup=gfindb)

466 (95) and several predicted transcriptional terminators 3' to the pat1 coding sequence 467 (determined using WebGeSTer DB; http://pallab.serc.iisc.ernet.in/gester/) (96). 
To express Pat1 in E. coli for antibody generation, the DNA sequence encoding full length pat1 was amplified from $R$. parkeri genomic DNA by PCR and subcloned into a pET1 vector containing an N-terminal 6x His-tag, maltose binding protein (MBP) tag,

471 and TEV cleavage site (Addgene plasmid \#29656). Primers used for amplifying the insert 472 (5'-TACTTCCAATCCAATGTAGATATAAACAACAATAAGATTAGC-3' and 5'473 TTATCCACTTCCAATGAGATAACCTTGTACATCATCTGTATGC-3') contained 15-bp 474 overhang with homology to the plasmid for InFusion cloning (Takara Bio, 638947). The 475 resulting plasmid, pET-M1-6xHis-MBP-TEV-Pat1, was transformed into E. coli strain 476 BL21 codon plus RIL-Camr (DE3) (UC Berkeley QB3 Macrolab). To express Pat1 in E. coli for antibody affinity purification from rabbit sera, the DNA 478 sequence encoding full length pat1 was amplified from pET-M1-6xHis-MBP-TEV-Pat1 by 479 PCR and subcloned into the pSMT3 plasmid containing a 6xHis-tag upstream of the 480 SUMO tag (97). Primers used for amplifying insert (5'481 CACAGAGAACAGATTGGTGGATCCATGGTAGATATAAACAACAATAAGATTAG-3' 482 and 5'-GTGGTGGTGGTGGTGTAACTCGAGGAGATAACCTTGTACATCATCTGTAT 483 GC-3') contained 15-bp overhang with homology to the plasmid for InFusion cloning 484 (Takara Bio, 638947). The resulting plasmid, pSMT3-6x-His-SUMO-Pat1, was 485 transformed into E. coli strain BL21 codon plus RIL-Cam ${ }^{r}$ (DE3) (UC Berkeley QB3 486 Macrolab).

487 To make pmCherry-N1-Gal8, full-length Gal8 was amplified from PB-CAG488 mRuby3-Gal8-P2A-Zeo (Addgene plasmid \#150815) and subcloned into pmCherry-N1 489 (Clontech, 632523). Primers used for amplifying insert were 5'- 

GCGACCGGTGGATCCCCCCAGCTCCTTACTTCCAGT-3'. The forward primer

492 contained a Kozak sequence and both primers contained 15-bp overhang with homology 493 to the plasmid for InFusion cloning (Takara Bio, 638947). To make pmCherry-N1-Gal3, Gal3 CDNA was amplified using

primers 5'CGCGGATCCCGTATCATGGTATATGAAGCACTG-3' and subcloned into pmCherry$497 \quad$ N1.

\section{R. parkeri strains and bacterial isolation}

R. parkeri Portsmouth strain (WT) was provided by Dr. Christopher Paddock

501 (Centers for Disease Control and Prevention). The pat1::Tn mutant was generated from

502 this strain as described previously (60). R. parkeri strains were purified by infecting

503 confluent Vero cells in T175 flasks at an MOI of 0.05 . Flasks were monitored for plaque

504 formation and harvested when $70-80 \%$ of the cells in the flask were rounded, typically 5-

$5057 \mathrm{~d}$ after infection. Cells were scraped and pelleted at $12,000 \times \mathrm{g}$ for $30 \mathrm{~min}$ at $4^{\circ} \mathrm{C}$. The

506 pelleted cells were resuspended in ice-cold $\mathrm{K} 36$ buffer $\left(0.05 \mathrm{M} \mathrm{KH}_{2} \mathrm{PO}_{4}, 0.05 \mathrm{M} \mathrm{K}_{2} \mathrm{HPO}_{4}\right.$,

$507 \mathrm{pH} 7.0,100 \mathrm{mM} \mathrm{KCl}, 15 \mathrm{mM} \mathrm{NaCl}$ ) and transferred to a Dounce homogenizer. Repeated

508 douncing of $60-80$ strokes released intracellular bacteria and the lysed cells and bacteria

509 were centrifuged at $200 \times \mathrm{g}$ for $5 \mathrm{~min}$ at $4^{\circ} \mathrm{C}$. The supernatant containing the bacteria was

510 overlaid on a 30\% MD-76R solution (Bracco Diagnostics, NDC 0270-0860-30) and

511 centrifuged at $18,000 \mathrm{rpm}$ for $30 \mathrm{~min}$ at $4^{\circ} \mathrm{C}$ in a SW-28 rotor to further separate host cell 
512 components from bacteria. Bacterial pellets were resuspended in brain heart infusion

$513(\mathrm{BHI})$ media (BD Difco, 237500) and stored at $-80^{\circ} \mathrm{C}$. Purified bacteria are referred to as

514 "30\% preparations" below.

515 For complementation of the pat1::Tn mutant, small scale electroporations were

516 performed with pMW1650-Spec as previously described for pMW1650 (60). Following

517 electroporation, $200 \mu \mathrm{l}$ of bacteria per well were added to confluent Vero cells in a 6-well

518 plate. The plate was rocked at $37^{\circ} \mathrm{C}$ for $30 \mathrm{~min}$ in a humidified chamber. An overlay of

519 Vero media with 5\% FBS and $0.5 \%$ agarose was added to each well and incubated at

$52033^{\circ} \mathrm{C}, 5 \% \mathrm{CO}_{2}$ for $24 \mathrm{~h}$. To select for transformants, an overlay of Vero media with $5 \%$

521 FBS, $0.5 \%$ agarose, and $40 \mu \mathrm{M}$ spectinomycin was added to the cells for plaque isolation.

522 Individual plaques were picked and resuspended in $200 \mu \mathrm{l} \mathrm{BHI}$ media. To grow plaque-

523 isolated bacteria, plaques were added to Vero cells in a T25 flask and rocked at $37^{\circ} \mathrm{C}$ for

$52430 \mathrm{~min}$. Spectinomycin was added to $40 \mu \mathrm{M}$ final concentration, and the flasks were

525 placed at $33^{\circ} \mathrm{C}$ and monitored for bacterial growth and harvested when $70-80 \%$ of the

526 cells in the flask were rounded, typically 5-7 d after infection. Infected cells were scraped

527 from the flask and pelleted at 2,000 $\times \mathrm{g}$ for $5 \mathrm{~min}$ at room temperature followed by

528 resuspension in K36 buffer. Cells were mechanically disrupted by vortexing at $\sim 2,900$

529 rpm (Vortex Genie 2) with $1 \mathrm{~mm}$ glass beads for two 30 s pulses with $30 \mathrm{~s}$ incubations on

530 ice after each pulse. Following disruption, host cell debris was pelleted by centrifuging at

$531200 \times \mathrm{g}$ for $5 \mathrm{~min}$ at $4^{\circ} \mathrm{C}$. The supernatant was transferred to pre-chilled microcentrifuge

532 tubes and spun at $10,000 \times \mathrm{g}$ for $2 \mathrm{~min}$ at $4^{\circ} \mathrm{C}$ to pellet $R$. parkeri. Bacterial pellets were

533 washed three times with cold $250 \mathrm{mM}$ sucrose, then resuspended in $200 \mu \mathrm{BHI}(50 \mu \mathrm{l}$ 
534 was frozen at $-80^{\circ} \mathrm{C}$ ). To further expand the bacterial population, $150 \mu \mathrm{l}$ of bead-prepped

535 bacteria was mixed with $350 \mu$ of Vero media and added to Vero cells in a T75 flask,

536 rocked at $37^{\circ} \mathrm{C}$ for $30 \mathrm{~min}$, supplemented with Vero media to a final volume of $12 \mathrm{ml}$, and

537 incubated at $33^{\circ} \mathrm{C}$ in $5 \% \mathrm{CO}_{2}$. After $5-7 \mathrm{~d}$, when $70-80 \%$ of the cells in the flask were

538 rounded, the process of bead disruption and bacteria isolation was repeated, except the

539 bacteria were resuspended in $\mathrm{BHI}$ without any sucrose washes to generate frozen stocks

540 that were stored at $-80^{\circ} \mathrm{C}$. Bacterial strains were screened by PCR for the following: (1)

541 the presence of the original transposon using primers for the rifampicin resistance

542 cassette (primers 5'- ATGGTAAAAGATTGGATTCCTATTTCTC-3' and 5'-

543 CCTTAATCTTCAATAACATGT-3'); (2) the presence of second transposon using primers

544 for spectinomycin resistance cassette (primers 5'-TGATTTGCTGGTTACGGTGAC-3'

545 and 5'-CGCTATGTTCTCTTGCTTTTG-3'); and (3) the presence of pat1::Tn and WT pat1

546 using primers amplifying pat1 (primers 5'-GTAGATATAAACAACAATAAGATTAGC-3'

547 and 5'-GAGATAACCTTGTACATCATCTGTATGC-3'). Strains were also screened by

548 assessing plaque size and Pat1 expression by western blot (procedure described below).

549 The pat1::Tn pat1+ strain that contained the original transposon, the second transposon,

550 plaque size similar to $\mathrm{WT}$, and restored Pat1 protein levels was propagated to purify

551 bacterial $30 \%$ preparations as described above.

552 The insertion site of the transposon was mapped as previously described (93).

553 Briefly, R. parkeri genomic DNA was purified from frozen $30 \%$ preparations of bacteria

$554\left(\sim 10^{8} \mathrm{PFU}\right)$. Bacteria were thawed and centrifuged at $8,000 \mathrm{rpm}$ for $5 \mathrm{~min}$ to pellet

555 bacteria, then genomic DNA was purified using DNeasy Blood and Tissue kit (Qiagen, 
556 69504), according to the manufacturer's protocol for Gram-negative bacteria (except that

557 the proteinase $\mathrm{K}$ incubation was done overnight). $1 \mu \mathrm{g}$ of $R$. parkeri genomic DNA was

558 digested with HindIII (New England Biolabs, R0104T). The reaction was heat-inactivated

559 and DNA fragments were self-ligated using T4 DNA ligase (New England Biolabs,

560 M0202T). E. coli were transformed with the ligation reaction and plated onto Luria-Bertani

561 (LB) agar plates with $40 \mu \mathrm{M}$ spectinomycin to select for plasmids containing the

562 pMW1650-Spec transposon and flanking regions of genomic DNA. Plasmid DNA was

563 sequenced (primers 5'-ATCTCGCTTTACCTTGGATTCC-3' and 5'-

564 CTATACGAAGTTGGGCATAC-3') to determine the genomic location of the insertion site.

565 The insertion site was then confirmed by PCR from genomic DNA using primers that flank

566 the insertion region (5'-AAAGCGGGAATCCAGTAAATC-3' and 5'-

567 GGCACAGCAGAAATTACTCTTG-3').

\section{Plaque assays and growth curves}

570 To determine the titer of purified bacteria, $200 \mu$ l of bacteria diluted $10^{-3}-10^{-8}$ in Vero media

571 were added to Vero cells grown in 6-well plates. Plates were rocked at $37^{\circ} \mathrm{C}$ for $30 \mathrm{~min}$

572 then overlaid with $3 \mathrm{ml}$ of Vero media with $5 \%$ FBS and $0.7 \%$ agarose. For imaging

573 plaques, neutral red $(0.01 \%$ final concentration; Sigma, N6264) in Vero media with $2 \%$

574 FBS and $0.5 \%$ agarose was overlaid onto cells 5-7 d post infection. Because of

575 differences in timing of plaque formation for the WT and pat $1:$ Tn mutant strains, plaque

576 counts for WT and complemented pat1::Tn plaques were done at $\sim 5 \mathrm{~d}$ post infection, and 
577 those for pat $1:: T n$ plaques were done at $\sim 7 \mathrm{~d}$ post infection. Plaques were counted and 578 imaged $24 \mathrm{~h}$ after addition of neutral red.

579 Growth curves were carried out following infection of HMECs at an MOI of 0.01 in 580 24-well plates. At each time point, media was aspirated from individual wells, cells were 581 washed twice with sterile deionized water, $1 \mathrm{ml}$ of sterile deionized water was added, and 582 cells were lysed by repeated pipetting. Three serial dilutions of the supernatant from lysed 583 cells in Vero media, totaling $1 \mathrm{ml}$ each, were added in duplicate to confluent Vero cells in 584 12-well plates. Plates were spun at $300 \times \mathrm{g}$ for $5 \mathrm{~min}$ at room temperature and incubated 585 at $33^{\circ} \mathrm{C}$ overnight. The next day, media was aspirated and $2 \mathrm{ml}$ of Vero media with $5 \%$ 586 FBS and $0.7 \%$ agarose was overlaid in each well. Once plaques were visible, an overlay 587 with neutral red was done as described above. Because of differences in timing of plaque 588 formation noted above, plaque counts for WT and complemented pat1::Tn plaques were 589 done at $\sim 5 \mathrm{~d}$ post infection and those for pat1::Tn plaques were done at $\sim 7 \mathrm{~d}$ post 590 infection.

Pat1 expression and antibody generation

For expression of 6xHis-MBP-TEV-Pat1, E. coli strain BL21 codon plus RIL-Cam ${ }^{r}$ 594 (DE3) with plasmid pET-M1-6xHis-MBP-TEV-Pat1 was grown in LB with $25 \mathrm{mM}$ glucose 595 an $\mathrm{OD}_{600}$ of 0.5 and expression was induced with $1 \mathrm{mM} \mathrm{IPTG}$ for $1 \mathrm{~h}$ at $37^{\circ} \mathrm{C}$. Bacteria 596 were pelleted by spinning at $4,000 \mathrm{rpm}$ for $30 \mathrm{~min}$ at $4^{\circ} \mathrm{C}$, and the pellet was resuspended 597 in MBP lysis buffer (50 mM Tris- $\mathrm{HCl}, \mathrm{pH}$ 8.0, $300 \mathrm{mM} \mathrm{NaCl}, 1 \mathrm{mM}$ EDTA) supplemented 598 with $1 \mu \mathrm{g} / \mathrm{ml}$ each leupeptin (MilliporeSigma, L2884), pepstatin (MilliporeSigma, P5318), 
599

600

601

602

603

604

605

606

607

608

609

610

611

612

613

614

615

616

617

618

619

620

and chymostatin (MilliporeSigma, E16), and $1 \mathrm{mM}$ phenylmethylsulfonyl fluoride (PMSF, MilliporeSigma, 52332). Bacteria were flash frozen in liquid nitrogen and stored at $-80^{\circ} \mathrm{C}$. Bacterial cultures were thawed quickly and kept on ice or at $4^{\circ} \mathrm{C}$ for the remaining steps. Lysozyme (Sigma, L4919) was added to a final concentration of $1 \mathrm{mg} / \mathrm{ml}$ followed by a 15 min incubation on ice. Bacteria were subjected to 8 cycles of sonication at $30 \%$ power for $12 \mathrm{~s}$ bursts, followed by rest on ice for $30 \mathrm{~s}$. Lysed bacteria were spun at 13,000 rpm for $30 \mathrm{~min}$ at $4^{\circ} \mathrm{C}$. The supernatant was passed three times over a column of $10 \mathrm{ml}$ of amylose resin (New England Biolabs, E8031L). The column was washed with MBP wash buffer (50 mM Tris- $\mathrm{HCl}, \mathrm{pH} 8.0,300 \mathrm{mM} \mathrm{NaCl}$ ) by passing 15 column volumes. Bound protein was eluted by adding 2-3 column volumes of MBP elution buffer $(50 \mathrm{mM}$ Tris- $\mathrm{HCl}$, $\mathrm{pH} 8.0,300 \mathrm{mM} \mathrm{NaCl}, 0.5 \mathrm{mM}$ DTT, $10 \mathrm{mM}$ maltose) to the column and collecting $500 \mu \mathrm{l}$ fractions. Fractions were checked for eluted protein by both Bradford assay and SDSPAGE, and fractions with the highest concentration of protein and a single band at the expected molecular weight for MBP-Pat1 were pooled and concentrated.

To generate rabbit anti-Pat1 antibodies, $1.7 \mathrm{mg}$ of purified MBP-Pat1 was sent to Pocono Rabbit Farm and Laboratory. Immunization was carried out following their 91-day custom antibody production protocol, then extended for an additional 6 weeks for an additional boost and bleed before final exsanguination.

To affinity purify anti-Pat1 antibodies, E. coli strain BL21 codon plus RIL-Cam ${ }^{r}$ (DE3) with plasmid pSMT3-6x-His-SUMO-Pat1 was grown, induced for protein expression, and isolated as described above. Bacterial pellets were resuspended in His lysis buffer (20 mM Tris- $\mathrm{HCl}, \mathrm{pH} 8.0,300$ mM NaCl, 10 mM imidazole) supplemented with 
621 protease inhibitors PMSF and LPC at the same concentrations as described above.

622 Bacteria were lysed by sonication and the lysate centrifuged as described above. The

623 supernatant was incubated with $2.0 \mathrm{ml}$ of Ni-NTA resin (Qiagen, 30210) for $1 \mathrm{~h}$ at $4^{\circ} \mathrm{C}$

624 with rotation and the resin was applied to a column. The column was washed with His

625 wash buffer (20 mM Tris-HCL, $\mathrm{pH} 8.0,300 \mathrm{mM} \mathrm{NaCl}, 30 \mathrm{mM}$ imidazole), and protein was

626 eluted from the column in $500 \mu$ l aliquots with 2 column volumes of His elution buffer (50

$627 \mathrm{mM} \mathrm{NaH}_{2} \mathrm{PO}_{4}, \mathrm{pH} 8.0,300 \mathrm{mM} \mathrm{NaCl}, 250 \mathrm{mM}$ imidazole). The same protocol was

628 followed to purify 6x-His-SUMO from E. coli strain BL21 codon plus RIL-Cam (DE3)

629 transformed with the parental plasmid pSMT3. Purified 6x-His-SUMO or 6x-His-SUMO-

630 Pat1 were coupled to NHS-activated Sepharose 4 fast flow resin (GE Healthcare, 17-

631 0906-01) in ligand coupling buffer (200 mM NaHCO $3, \mathrm{pH} 8.3,500 \mathrm{mM} \mathrm{NaCl})$ for 2-4 h at

632 room temperature. To remove anti-SUMO antibodies, the 6x-His-Sumo resin was

633 incubated with $10 \mathrm{ml}$ anti-Pat1 serum diluted in binding buffer (20mM Tris- $\mathrm{HCl}, \mathrm{pH} 7.5)$

634 and incubated at $4^{\circ} \mathrm{C}$ for $2 \mathrm{~h}$ with rotation. The flow through was collected and added to

635 the $6 \mathrm{x}$-His-SUMO-Pat1 resin and was incubated at $4^{\circ} \mathrm{C}$ for $4 \mathrm{~h}$ with rotation. Bound

636 antibody was eluted with $100 \mathrm{mM}$ glycine, $\mathrm{pH} 2.5$, into tubes containing $120 \mu \mathrm{l} 1 \mathrm{M}$ Tris-

$637 \mathrm{HCl}, \mathrm{pH} 8.8$, to neutralize to $\mathrm{pH}$ 7.5. Eluted fractions were dialyzed in phosphate-buffered 638 saline (PBS; $137 \mathrm{mM} \mathrm{NaCl}, 2.7 \mathrm{mM} \mathrm{KCl}, 10 \mathrm{mM} \mathrm{Na}_{2} \mathrm{PO}_{4}, 1.8 \mathrm{mM} \mathrm{KH}_{2} \mathrm{PO}_{4}, \mathrm{pH}$ 7.4) with $63950 \%$ glycerol $(\mathrm{pH} 8.0)$ overnight at $4^{\circ} \mathrm{C}$, concentrated and stored at $-20^{\circ} \mathrm{C}$. 
$6431 \times$ SDS loading buffer (150 mM Tris pH 6.8, 6\% SDS, $0.3 \%$ bromophenol blue, $30 \%$

644 glycerol, $15 \% \beta$-mercaptoethanol) for $10 \mathrm{~min}$, resolved on a $10 \%$ SDS-PAGE gel, then

645 transferred to a PVDF membrane (Millipore, IPFL00010). The membrane was blocked 646 overnight at $4^{\circ} \mathrm{C}$ in TBS-T (20 mM Tris, $150 \mathrm{mM} \mathrm{NaCl}, \mathrm{pH}$ 8.0, 0.1\% Tween 20 (Sigma, 647 P9416) plus 5\% dry milk (Apex, 20-241). Affinity purified anti-Pat1 antibody was diluted $6481: 1,000$ in TBS-T plus $5 \%$ dry milk and incubated with the membrane overnight at $4^{\circ} \mathrm{C}$. 649 Anti-RickA (98) was used as a loading control by diluting serum 1:2,000 in TBS-T plus $6505 \%$ dry milk and incubating at room temperature for $1 \mathrm{~h}$. Membranes were washed with 651 TBS-T for 5 x 5 min intervals at room temperature. Secondary antibody goat anti-rabbit 652 HRP (Santa Cruz Biotechnology, sc-2004) was diluted 1:3,000 in TBS-T plus 5\% dry milk 653 and incubated at RT for $30 \mathrm{~min}$, followed by $5 \times 5 \mathrm{~min}$ washes with TBS-T. To detect 654 secondary antibodies, ECL HRP substrate kit (Advansta, K-12045) was added to the 655 membrane for $45 \mathrm{~s}$ at room temperature and developed using Biomac Light film 656 (Carestream, 178-8207).

\section{Bacterial infections for imaging} Infections were carried out in 24-well plates unless otherwise noted. For 660 immunofluorescence microscopy, 24-well plates containing $12 \mathrm{~mm}$ sterile coverslips were 661 used. HMECs were seeded at $2.5 \times 10^{5}$ cells/well and infected $36-48 \mathrm{~h}$ later. A549 cells were seeded at $1.2 \times 10^{5}$ cells/well and infected $24 \mathrm{~h}$ later. For timepoints from $0-2 \mathrm{hpi}$, an $663 \mathrm{MOI}$ of 3-5 was used for all cell types, and for 24-48 hpi, an MOI of 0.01-0.05 was used. 
664 For the infectious focus assay, an MOI of 0.001 was used. To infect cells, a $30 \%$

665 preparation of $R$. parkeri was thawed on ice prior to infection and immediately diluted into

666 fresh media on ice. Cell media was aspirated, the well was washed once with PBS (Gibco,

667 10010049), $0.5 \mathrm{ml}$ of bacteria in media was added per well, and the plate was spun at

$668300 \times \mathrm{g}$ for $5 \mathrm{~min}$ at room temperature. Media at $33^{\circ} \mathrm{C}$ was added following centrifugation

669 and infected cells were incubated at $33^{\circ} \mathrm{C}$ in $5 \% \mathrm{CO}_{2}$.

670 For Gal3 and Gal8 imaging experiments, HMECs were transfected with pmCherry-

671 N1-Gal3 or pmCherry-N1-Gal8 using Lipofectamine LTX (Invitrogen, A12621) and

672 incubated at $37^{\circ} \mathrm{C}$ overnight. The next morning, wells were washed twice with PBS and

673 replaced with fresh, warm HMEC media. Cells were visually examined to confirm 80-

$674100 \%$ confluency and the presence of Gal3 or Gal8 expression. Infections were

675 performed a few hours later.

676

The mixed cell assay was adapted from a prior study (67). Briefly, A549-TRTF cells

677 and unlabeled A549 cells were seeded into 12-well plates at a density of $3 \times 10^{5}$ cells $/ \mathrm{ml}$

678 and grown overnight. The following day, A549-TRTF cells were infected at an MOI of 5

679 as described above and incubated at $33^{\circ} \mathrm{C}$ for $1 \mathrm{~h}$. Both infected A549-TRTF cells and

680 unlabeled A549 cells were detached by adding warm citric saline (135 mM KCl, $15 \mathrm{mM}$

681 sodium citrate) and incubating for $5 \mathrm{~min}$ at $37^{\circ} \mathrm{C}$. Cells were gently resuspended by

682 pipetting up and down and recovered in A549 media, then washed twice with A549 media.

683 Cells were resuspended in A549 media with $10 \mu \mathrm{g} / \mathrm{ml}$ gentamycin to kill extracellular 
685 on coverslips in a 24-well plate, and incubated in a humidified secondary container at $68633^{\circ} \mathrm{C}$ until 32 hpi. were infected as stated above and incubated for $5 \mathrm{~min}$ at $37^{\circ} \mathrm{C}$, at which point media was exchanged with a hypertonic solution (10\% PEG-1000, $0.5 \mathrm{M}$ sucrose in PBS) and

690 incubated at $37^{\circ} \mathrm{C}$ for $10 \mathrm{~min}$. Wells were washed gently once with the hypotonic solution

691 (60\% PBS), incubated in hypotonic solution at $37^{\circ} \mathrm{C}$ for $3 \mathrm{~min}$, then incubated in isotonic HMEC media for $15 \mathrm{~min}$ at $37^{\circ} \mathrm{C}$.

Immunofluorescence microscopy

All coverslips were fixed for $10 \mathrm{~min}$ in fresh $4 \%$ paraformaldehyde (Ted Pella, 18505) at room temperature. Coverslips were washed 3x with PBS pH 7.4 and stored at $6974^{\circ} \mathrm{C}$ until staining. All antibodies were diluted in PBS with $2 \%$ BSA (Sigma, A9418). All 698 incubations were done at room temperature unless otherwise noted and all coverslips 699 were mounted in Prolong Gold antifade (Invitrogen, P36930) and sealed with nail polish 700 after drying. Primary antibodies used to stain Rickettsia were rabbit anti-Rickettsia 17205 702 (1:300; (99)); gift from T. Hackstadt), rabbit anti-Rickettsia OmpB (1:1,000; (82)), and 703 mouse anti-Rickettsia 14-13 (1:400; (99)); gift from T. Hackstadt). Primary antibodies 704 were incubated with coverslips for $30 \mathrm{~min}$. Coverslips were washed $3 \mathrm{x}$ with PBS and the 705 following secondary antibodies were added for $30 \mathrm{~min}$, protected from light: goat anti706 rabbit Alexa 488 (1:400; Invitrogen, A11008), goat anti-rabbit Alexa 404 (1:150; 
707 Invitrogen, A31556), goat anti-mouse Alexa 488 (1:400; Invitrogen, A11001), and goat 708 anti-mouse Alexa 404 (1:150; Invitrogen, A31553).

709 To quantify colocalization with polyubiquitin and autophagy adapters, cells were 710 permeabilized with $0.5 \%$ Triton-X100 and washed three times with PBS. Primary 711 antibodies were added for $30 \mathrm{~min}$ to $1 \mathrm{~h}$ at the following dilutions: mouse anti-polyubiquitin

712 FK1 (1:250; EMD Millipore, 04-262), guinea pig anti-p62 (1:500; Fitzgerald, 20R-PP001), 713 mouse anti-NDP52 (1:300; Novus Biologicals, H00010241-B01P). For staining with rabbit 714 polyclonal anti-LC3 (1:250; Novus Biologicals, NB100-2220SS) and mouse anti-human 715 Lamp1 (1:25; BD Bioscience, 555801), cells were post-fixed in 100\% methanol at room 716 temperature for 5 min. After antibody incubations, coverslips were washed $3 x$ with PBS 717 and the following secondary antibodies were added for $30 \mathrm{~min}$ and protected from the 718 light: goat anti-mouse Alexa 568 (1:500; Invitrogen, A11004), goat anti-mouse Alexa 488 719 (1:400; Invitrogen, A11001), anti-guinea pig Alexa 568 (1:500; Invitrogen, A11075), and 720 anti-guinea pig Alexa 488 (1:400; Invitrogen, A11073). Coverslips were then washed 721 three times with PBS. To quantify the percent of bacteria with actin tails, cells were permeabilized with

$7230.5 \%$ Triton-X100 for 5 min then washed three times with PBS. Rickettsia were stained 724 with either anti-Rickettsia $14-13$ or anti-Rickettsia 17205 as described above. After 725 staining for Rickettsia, actin was stained with phalloidin-568 (diluted 1:500 in PBS with $7262 \%$ BSA; Life Technologies, A12380) for $30 \mathrm{~min}$ at room temperature. Coverslips were 727 then washed three times with PBS. 
To quantify the percent of bacteria with actin tails in the mixed cell assay, cells were permeabilized with $0.1 \%$ Triton-X100 for 5 min then washed three times with PBS. Rickettsia was detected with the primary antibody mouse anti-Rickettsia 14-13 and the

731 secondary antibody goat anti-mouse Alexa 404 as described above. After staining for

732 Rickettsia, actin was stained with phalloidin-488 (diluted 1:400 in PBS with 2\% BSA; Life

733 Technologies, P3457) for $30 \mathrm{~min}$ at room temperature. Coverslips were then washed 734 three times with PBS.

736 Triton-X100 for 5 min, washed three times with PBS, and blocked with PBS containing $7372 \%$ BSA for $1 \mathrm{~h}$. Coverslips were incubated with anti- $\beta$-catenin (1:200; BD Bioscience, 738 610153) for $1 \mathrm{~h}$ at room temperature, then washed three times with PBS, followed by 739 incubation with goat anti-mouse Alexa-568 (1:500; Invitrogen, A11004) for 30 min 740 protected from the light. Cells were subsequently stained to detect Rickettsia with anti$741 \quad 17205$ for 30 min and goat anti-rabbit Alexa 488 as described above. Nuclei were stained 742 with Hoechst (1:10,000; Thermo Scientific, 62249) for $15 \mathrm{~min}$. To quantify, the number of 743 infected cells per focus was counted for $10-15$ foci per experiment.

Transmission electron microscopy

HMEC- 1 cells were seeded into 6-well plates $\left(1 \times 10^{6}\right.$ cells per well) and grown for

$74736 \mathrm{~h}$. Media was aspirated and $2.5 \mathrm{ml}$ of bacteria in media at an MOI of 5 were added.

748 The plates were spun at $300 \times \mathrm{g}$ for $5 \mathrm{~min}$ at room temperature, then $2.5 \mathrm{ml}$ of warm

749 HMEC-1 media was added to each well, and the plates were placed at $33^{\circ} \mathrm{C}$. Time points 
were taken by aspirating media, washing the well with PBS, and fixing the cells in fixative

751 (2\% paraformaldehyde, $2 \%$ glutaraldehyde in $0.05 \mathrm{M}$ cacodylate buffer, $\mathrm{pH} 7.2$ ) for $45 \mathrm{~min}$

752 at room temperature. Cells were scraped and pelleted in microcentrifuge tubes and stored

753 in fresh fixative at $4^{\circ} \mathrm{C}$ until embedding. Samples were embedded in $2 \%$ low melt agarose

754 and placed in $2 \%$ glutaraldehyde in $1 \mathrm{M}$ cacodylate buffer, $\mathrm{pH} 7.2$, and stored at $4^{\circ} \mathrm{C}$

755 overnight. The next day, samples were post-fixed with $1 \%$ osmium tetraoxide and $1.6 \%$

756 potassium ferricyanide, then dehydrated in increasing concentrations of ice-cold ethanol

757 (70\%-100\%). Samples were embedded in Epon 812 resin (11.75g Epon 12, 6.25g

758 dodecenyl succinic anhydride, $7 \mathrm{~g}$ nadic methyl anhydride, and $0.375 \mathrm{ml}$ of the accelerator

759 benzyldimethylamine was added during the dehydration step) and stained with $2 \%$ uranyl

760 acetate and lead citrate. Images were captured with a FEI Tecani 12 transmission

761 electron microscope and analyzed manually to determine the total number of intracellular

762 bacteria and their respective localizations within the cell.

763

764

Mouse Studies

765

Animal research was conducted under a protocol approved by the University of

766

California, Berkeley Institutional Animal Care and Use Committee (IACUC) in compliance

767 with the Animal Welfare Act and other federal statutes relating to animals and

768 experiments using animals (Welch lab animal use protocol AUP-2016-02-8426-1). Mice

769 were 8-20 weeks old at the time of initial infection. Mice were selected for experiments

770 based on their availability, regardless of sex, and both sexes were used for each

771 experimental group. All mice were of the C57BL/6J background were double knock outs 
772 for the genes encoding the receptors for IFN-I (Ifnar1) and IFN- $\gamma$ (Ifngr1) (Ifnar1-/-;Ifngr1-

773 /-) (Jackson Labs stock \#:029098, described in (61)) and were healthy at the time of

774 infection. R. parkeri was prepared by diluting $30 \%$ preparation bacteria into $1 \mathrm{ml}$ cold

775 sterile PBS on ice, centrifuging the bacteria at $12,000 \times g$ for $1 \mathrm{~min}$, and resuspending in

776 cold sterile PBS to the desired concentration $\left(5 \times 10^{6} \mathrm{PFU} / \mathrm{ml}\right.$ for intravenous infection).

777 The bacterial suspensions were kept on ice during injections. Mice were exposed to a

778 heat lamp while in their cages for approximately $5 \mathrm{~min}$ and then each mouse was moved

779 to a mouse restrainer (Braintree, TB-150 STD). The tail was sterilized with $70 \%$ ethanol,

780 and $200 \mu \mathrm{l}$ bacterial suspensions were injected using 30.5-gauge needles into the lateral

781 tail vein. Body temperatures were monitored using a rodent rectal thermometer

782 (BrainTree Scientific, RET-3). Mice were euthanized if their body temperature fell below

$78390^{\circ} \mathrm{F}\left(32.2^{\circ} \mathrm{C}\right)$ or if they exhibited severe lethargy that prevented their normal movement

784 around the cage.

785

786 Statistics

787 The statistical parameters and significance are reported in the figure legends. Data

788 were considered to be statistically significant when $P<0.05$, as determined by an

789 unpaired Student's t-test, a one-way ANOVA with either multiple comparisons or

790 comparison to WT bacteria, a two-way ANOVA, or a log-rank (Mantel-Cox) test. Asterisks

791 denote statistical significance as: ${ }^{*} P<0.05 ;{ }^{* *} P<0.01 ;{ }^{* *} P<0.001 ;{ }^{* * * *} P<0.0001$,

792 compared with the indicated controls. Statistical analyses were performed using

793 GraphPad PRISM v.9. 


\section{Acknowledgements}

797 We thank Ted Hackstadt, David Wood, and Christopher Paddock for kindly providing 798 strains and reagents. We thank previous Welch Lab members whose work supported this 799 project, including Rebecca Lamason, Natasha Kafai, Julie Choe, and Shawna Reed, and 800 current lab members for critical feedback throughout the development of this project. We 801 also thank the following UC Berkeley core facilities and their facility members for providing 802 equipment, reagents, and technical support to complete this work: Danielle Jorgens, 803 Reena Zalpuri, and Guangwei Min (UC Berkeley Electron Microscope Laboratory); Holly 804 Aaron and Feather Ives (CRL Molecular Imaging Center); and Alison Killilea (Cell Culture 805 Facility). We thank David Drubin, Karsten Gronert, and Daniel Portnoy for technical 806 discussion and critical guidance for this work. We also thank Neil Fischer for proofreading 807 the manuscript. This work was funded by grant R01 Al109044 from the NIH/NIAID to 808 M.D.W.

\section{References}

812 1. Parola P, Paddock CD, Socolovschi C, Labruna MB, Mediannikov O, Kernif T, 813 Abdad MY, Stenos J, Bitam I, Fournier P-E, Raoult D. 2013. Update on tick-borne rickettsioses around the world: a geographic approach. Clin Microbiol Rev 26:657702. 
816 2. Blanton LS. 2019. The Rickettsioses: A Practical Update. Infect Dis Clin North Am

$817 \quad 33: 213-229$.

818 3. Jay R, Armstrong PA. 2020. Clinical characteristics of Rocky Mountain spotted fever in the United States: A literature review. J Vector Borne Dis 57:114-120.

4. Herrick KL, Pena SA, Yaglom HD, Layton BJ, Moors A, Loftis AD, Condit ME, Singleton J, Kato CY, Denison AM, Ng D, Mertins JW, Paddock CD. 2016. Rickettsia parkeri Rickettsiosis, Arizona, USA. Emerg Infect Dis 22:780-785.

5. Paddock CD, Finley RW, Wright CS, Robinson HN, Schrodt BJ, Lane CC, Ekenna O, Blass MA, Tamminga CL, Ohl CA, McLellan SLF, Goddard J, Holman RC, Openshaw JJ, Sumner JW, Zaki SR, Eremeeva ME. 2008. Rickettsia parkeri rickettsiosis and its clinical distinction from Rocky Mountain spotted fever. Clin Infect Dis 47:1188-1196.

6. Grasperge BJ, Reif KE, Morgan TD, Sunyakumthorn P, Bynog J, Paddock CD, Macaluso KR. 2012. Susceptibility of inbred mice to Rickettsia parkeri. Infect

831 7. Saito TB, Bechelli J, Smalley C, Karim S, Walker DH. 2019. Vector Tick Transmission Model of Spotted Fever Rickettsiosis. Am J Pathol 189:115-123.

8. Burke TP, Engström P, Tran CJ, Langohr IM, Glasner DR, Espinosa DA, Harris E, Welch MD. 2021. Interferon receptor-deficient mice are susceptible to escharassociated rickettsiosis. Elife 10:e67029. 
836

837

838

839

840

841

842

843

844

845

846

847

848

849

850

851

852

853

854

855

9. Londoño AF, Mendell NL, Walker DH, Bouyer DH. 2019. A biosafety level-2 dosedependent lethal mouse model of spotted fever rickettsiosis: Rickettsia parkeri Atlantic Rainforest strain. PLoS Negl Trop Dis 13:e0007054.

10. Narra HP, Sahni A, Walker DH, Sahni SK. 2020. Recent research milestones in the pathogenesis of human rickettsioses and opportunities ahead. Future Microbiol $15: 753-765$.

11. Voss OH, Rahman MS. 2021. Rickettsia-host interaction: strategies of intracytosolic host colonization. Pathog Dis 79(4):ftab015.

12. Lamason RL, Welch MD. 2017. Actin-based motility and cell-to-cell spread of bacterial pathogens. Curr Opin Microbiol 35:48-57.

13. Bajunaid W, Haidar-Ahmad N, Kottarampatel AH, Ourida Manigat F, Silué N, Tchagang CF, Tomaro K, Campbell-Valois F-X. 2020. The T3SS of Shigella: Expression, Structure, Function, and Role in Vacuole Escape. Microorganisms $8(12): 1933$

14. Du J, Reeves AZ, Klein JA, Twedt DJ, Knodler LA, Lesser CF. 2016. The type III secretion system apparatus determines the intracellular niche of bacterial pathogens. Proc Natl Acad Sci U S A 113:4794-4799.

15. High N, Mounier J, Prévost MC, Sansonetti PJ. 1992. IpaB of Shigella flexneri causes entry into epithelial cells and escape from the phagocytic vacuole. EMBO J 11:1991-1999. 
856

857

858

859

860

861

862

863

864

865

866

867

868

869

870

871

872

873

874

16. Page AL, Ohayon H, Sansonetti PJ, Parsot C. 1999. The secreted IpaB and IpaC invasins and their cytoplasmic chaperone $\mathrm{IpgC}$ are required for intercellular dissemination of Shigella flexneri. Cell Microbiol 1:183-193.

17. Picking WL, Nishioka H, Hearn PD, Baxter MA, Harrington AT, Blocker A, Picking WD. 2005. IpaD of Shigella flexneri is independently required for regulation of Ipa protein secretion and efficient insertion of IpaB and IpaC into host membranes. Infect Immun 73:1432-1440.

18. Schuch R, Sandlin RC, Maurelli AT. 1999. A system for identifying post-invasion functions of invasion genes: requirements for the Mxi-Spa type III secretion pathway of Shigella flexneri in intercellular dissemination. Mol Microbiol 34:675689.

19. Alberti-Segui C, Goeden KR, Higgins DE. 2007. Differential function of Listeria monocytogenes listeriolysin $\mathrm{O}$ and phospholipases $\mathrm{C}$ in vacuolar dissolution following cell-to-cell spread. Cell Microbiol 9:179-195.

20. Beauregard KE, Lee KD, Collier RJ, Swanson JA. 1997. pH-dependent perforation of macrophage phagosomes by listeriolysin $\mathrm{O}$ from Listeria monocytogenes. $J$ Exp Med 186:1159-1163.

21. Portnoy DA, Jacks PS, Hinrichs DJ. 1988. Role of hemolysin for the intracellular growth of Listeria monocytogenes. J Exp Med 167:1459-1471. 
875 22. Schnupf P, Portnoy DA. 2007. Listeriolysin O: a phagosome-specific lysin.

876 Microbes Infect 9:1176-1187.

877

878

879

880

881

882

883

884

885

886

887

888

889

890

891

23. Burrack LS, Harper JW, Higgins DE. 2009. Perturbation of vacuolar maturation promotes listeriolysin O-independent vacuolar escape during Listeria monocytogenes infection of human cells. Cell Microbiol 11:1382-1398.

24. Camilli A, Tilney LG, Portnoy DA. 1993. Dual roles of plcA in Listeria monocytogenes pathogenesis. Mol Microbio/ 8:143-157.

25. Gründling A, Gonzalez MD, Higgins DE. 2003. Requirement of the Listeria monocytogenes broad-range phospholipase PC-PLC during infection of human epithelial cells. J Bacteriol 185:6295-6307.

26. Marquis H, Doshi V, Portnoy DA. 1995. The broad-range phospholipase $\mathrm{C}$ and a metalloprotease mediate listeriolysin O-independent escape of Listeria monocytogenes from a primary vacuole in human epithelial cells. Infect Immun 63:4531-4534.

27. Smith GA, Marquis H, Jones S, Johnston NC, Portnoy DA, Goldfine H. 1995. The two distinct phospholipases $\mathrm{C}$ of Listeria monocytogenes have overlapping roles in escape from a vacuole and cell-to-cell spread. Infect Immun 63:4231-4237.

28. Rahman MS, Ammerman NC, Sears KT, Ceraul SM, Azad AF. 2010. Functional characterization of a phospholipase A(2) homolog from Rickettsia typhi. J Bacteriol 192:3294-3303. 
895

896

897

898

899

900

901

902

903

904

905

906

907

908

909

910

911

912

913

29. Renesto P, Dehoux P, Gouin E, Touqui L, Cossart P, Raoult D. 2003. Identification and characterization of a phospholipase D-superfamily gene in rickettsiae. $J$ Infect Dis 188:1276-1283.

30. Driskell LO, Yu X, Zhang L, Liu Y, Popov VL, Walker DH, Tucker AM, Wood DO. 2009. Directed mutagenesis of the Rickettsia prowazekii pld gene encoding phospholipase D. Infect Immun 77:3244-3248.

31. Whitworth T, Popov VL, Yu X-J, Walker DH, Bouyer DH. 2005. Expression of the Rickettsia prowazekii pld or tlyC gene in Salmonella enterica serovar Typhimurium mediates phagosomal escape. Infect Immun 73:6668-6673.

32. Winkler HH, Daugherty RM. 1989. Phospholipase A activity associated with the growth of Rickettsia prowazekii in L929 cells. Infect Immun 57:36-40.

33. Winkler HH, Miller ET. 1982. Phospholipase A and the interaction of Rickettsia prowazekii and mouse fibroblasts (L-929 cells). Infect Immun 38:109-113.

34. Walker DH, Firth WT, Ballard JG, Hegarty BC. 1983. Role of phospholipaseassociated penetration mechanism in cell injury by Rickettsia rickettsii. Infect Immun 40:840-842.

35. Walker DH, Feng HM, Popov VL. 2001. Rickettsial phospholipase A2 as a pathogenic mechanism in a model of cell injury by typhus and spotted fever group rickettsiae. Am J Trop Med Hyg 65:936-942. 
914 36. Silverman DJ, Santucci LA, Meyers N, Sekeyova Z. 1992. Penetration of host cells by Rickettsia rickettsii appears to be mediated by a phospholipase of rickettsial origin. Infect Immun 60:2733-2740.

37. Rahman MS, Gillespie JJ, Kaur SJ, Sears KT, Ceraul SM, Beier-Sexton M, Azad AF. 2013. Rickettsia typhi possesses phospholipase A2 enzymes that are involved in infection of host cells. PLoS Pathog 9:e1003399.

38. Huang J, Brumell JH. 2014. Bacteria-autophagy interplay: a battle for survival. Nat Rev Microbiol 12:101-114.

39. Kirkin V, McEwan DG, Novak I, Dikic I. 2009. A role for ubiquitin in selective autophagy. Mol Cell 34:259-269.

40. Perrin AJ, Jiang X, Birmingham CL, So NSY, Brumell JH. 2004. Recognition of bacteria in the cytosol of Mammalian cells by the ubiquitin system. Curr Biol $14: 806-811$.

41. Johansen T, Lamark T. 2011. Selective autophagy mediated by autophagic adapter proteins. Autophagy 7:279-296.

42. Mostowy S, Sancho-Shimizu V, Hamon MA, Simeone R, Brosch R, Johansen T, Cossart P. 2011. p62 and NDP52 proteins target intracytosolic Shigella and Listeria to different autophagy pathways. J Biol Chem 286:26987-26995. 
934

935

936

937

938

\section{9}

940

941

942

943

944

945

946

947

948

949

950

951

952

degradation of ubiquitinated protein aggregates by autophagy. $J$ Biol Chem 282:24131-24145.

44. Zheng YT, Shahnazari S, Brech A, Lamark T, Johansen T, Brumell JH. 2009. The adaptor protein p62/SQSTM1 targets invading bacteria to the autophagy pathway. J Immunol 183:5909-5916.

45. Thurston TLM, Ryzhakov G, Bloor S, von Muhlinen N, Randow F. 2009. The TBK1 adaptor and autophagy receptor NDP52 restricts the proliferation of ubiquitincoated bacteria. Nat Immunol 10:1215-1221.

46. von Muhlinen N, Thurston T, Ryzhakov G, Bloor S, Randow F. 2010. NDP52, a novel autophagy receptor for ubiquitin-decorated cytosolic bacteria. Autophagy 6:288-289.

47. Kabeya Y, Mizushima N, Ueno T, Yamamoto A, Kirisako T, Noda T, Kominami E, Ohsumi Y, Yoshimori T. 2000. LC3, a mammalian homologue of yeast Apg8p, is localized in autophagosome membranes after processing. EMBO J 19:5720-5728.

48. Tanida I, Ueno T, Kominami E. 2004. LC3 conjugation system in mammalian autophagy. Int J Biochem Cell Biol 36:2503-2518.

49. Mitchell G, Ge L, Huang Q, Chen C, Kianian S, Roberts MF, Schekman R, Portnoy DA. 2015. Avoidance of autophagy mediated by PIcA or ActA is required for Listeria monocytogenes growth in macrophages. Infect Immun 83:2175-2184. 
953

954

955

956

957

958

959

960

961

962

963

964

965

966

967

968

969

970

971

50. Tattoli I, Sorbara MT, Yang C, Tooze SA, Philpott DJ, Girardin SE. 2013. Listeria phospholipases subvert host autophagic defenses by stalling pre-autophagosomal structures. EMBO J 32:3066-3078.

51. Hong M-H, Weng I-C, Li F-Y, Lin W-H, Liu F-T. 2021. Intracellular galectins sense cytosolically exposed glycans as danger and mediate cellular responses. J Biomed Sci 28:16.

52. Paz I, Sachse M, Dupont N, Mounier J, Cederfur C, Enninga J, Leffler H, Poirier F, Prevost M-C, Lafont F, Sansonetti P. 2010. Galectin-3, a marker for vacuole lysis by invasive pathogens. Cell Microbiol 12:530-544.

53. Weng I-C, Chen H-L, Lo T-H, Lin W-H, Chen H-Y, Hsu DK, Liu F-T. 2018. Cytosolic galectin-3 and -8 regulate antibacterial autophagy through differential recognition of host glycans on damaged phagosomes. Glycobiology 28:392-405.

54. Dupont N, Lacas-Gervais S, Bertout J, Paz I, Freche B, Van Nhieu GT, van der Goot FG, Sansonetti PJ, Lafont F. 2009. Shigella phagocytic vacuolar membrane remnants participate in the cellular response to pathogen invasion and are regulated by autophagy. Cell Host Microbe 6:137-149.

55. Thurston TLM, Wandel MP, von Muhlinen N, Foeglein A, Randow F. 2012. Galectin 8 targets damaged vesicles for autophagy to defend cells against bacterial invasion. Nature 482:414-418. 
972 56. Feeley EM, Pilla-Moffett DM, Zwack EE, Piro AS, Finethy R, Kolb JP, Martinez J,

973 Brodsky IE, Coers J. 2017. Galectin-3 directs antimicrobial guanylate binding

974 proteins to vacuoles furnished with bacterial secretion systems. Proc Natl Acad Sci

975 USA 114:E1698-E1706.

976 57. Mansilla Pareja ME, Bongiovanni A, Lafont F, Colombo MI. 2017. Alterations of the

977 Coxiella burnetii Replicative Vacuole Membrane Integrity and Interplay with the

$978 \quad$ Autophagy Pathway. Front Cell Infect Microbiol 7:112.

979 58. Bell SL, Lopez KL, Cox JS, Patrick KL, Watson RO. 2021. Galectin-8 Senses

59. Fujita N, Morita E, Itoh T, Tanaka A, Nakaoka M, Osada Y, Umemoto T, Saitoh T, Nakatogawa H, Kobayashi S, Haraguchi T, Guan J-L, Iwai K, Tokunaga F, Saito K, Ishibashi K, Akira S, Fukuda M, Noda T, Yoshimori T. 2013. Recruitment of the autophagic machinery to endosomes during infection is mediated by ubiquitin. $J$ Cell Biol 203:115-128.

60. Lamason RL, Kafai NM, Welch MD. 2018. A streamlined method for transposon mutagenesis of Rickettsia parkeri yields numerous mutations that impact infection. 
990

991

992

993

994

995

996

997

998

999

1000

1001

1002

1003

1004

1005

1006

1007

1008

1009

61. Burke TP, Engström P, Chavez RA, Fonbuena JA, Vance RE, Welch MD. 2020. Inflammasome-mediated antagonism of type I interferon enhances Rickettsia pathogenesis. Nat Microbiol 5:688-696.

62. Teysseire N, Boudier JA, Raoult D. 1995. Rickettsia conorii entry into Vero cells. Infect Immun 63:366-374.

63. Harris EK, Jirakanwisal K, Verhoeve VI, Fongsaran C, Suwanbongkot C, Welch MD, Macaluso KR. 2018. Role of Sca2 and RickA in the Dissemination of Rickettsia parkeri in Amblyomma maculatum. Infect Immun 86(6):e00123-18.

64. Reed SCO, Lamason RL, Risca VI, Abernathy E, Welch MD. 2014. Rickettsia actin-based motility occurs in distinct phases mediated by different actin nucleators. Curr Biol 24:98-103.

65. Okada CY, Rechsteiner M. 1982. Introduction of macromolecules into cultured mammalian cells by osmotic lysis of pinocytic vesicles. Cell 29:33-41.

66. Smith J, Manoranjan J, Pan M, Bohsali A, Xu J, Liu J, McDonald KL, Szyk A, LaRonde-LeBlanc N, Gao L-Y. 2008. Evidence for pore formation in host cell membranes by ESX-1-secreted ESAT-6 and its role in Mycobacterium marinum escape from the vacuole. Infect Immun 76:5478-5487.

67. Lamason RL, Bastounis E, Kafai NM, Serrano R, Del Álamo JC, Theriot JA, Welch MD. 2016. Rickettsia Sca4 Reduces Vinculin-Mediated Intercellular Tension to Promote Spread. Cell 167:670-683.e10. 
1010

1011

1012

1013

1014

1015

1016

1017

1018

1019

1020

1021

1022

1023

1024

1025

1026

1027

1028

1029

68. Kleba B, Clark TR, Lutter El, Ellison DW, Hackstadt T. 2010. Disruption of the Rickettsia rickettsii Sca2 autotransporter inhibits actin-based motility. Infect Immun 78:2240-2247.

69. Flores-Díaz M, Monturiol-Gross L, Naylor C, Alape-Girón A, Flieger A. 2016. Bacterial Sphingomyelinases and Phospholipases as Virulence Factors. Microbiol Mol Biol Rev 80:597-628.

70. Flores-Díaz M, Alape-Girón A. 2003. Role of Clostridium perfringens phospholipase C in the pathogenesis of gas gangrene. Toxicon 42:979-986.

71. O'Brien DK, Melville SB. 2004. Effects of Clostridium perfringens alpha-toxin (PLC) and perfringolysin $\mathrm{O}$ (PFO) on cytotoxicity to macrophages, on escape from the phagosomes of macrophages, and on persistence of $C$. perfringens in host tissues. Infect Immun 72:5204-5215.

72. Sato H, Frank DW. 2004. ExoU is a potent intracellular phospholipase. Mol Microbiol 53:1279-1290.

73. Bhanot P, Schauer K, Coppens I, Nussenzweig V. 2005. A surface phospholipase is involved in the migration of Plasmodium sporozoites through cells. $J$ Biol Chem 280:6752-6760.

74. Burda P-C, Roelli MA, Schaffner M, Khan SM, Janse CJ, Heussler VT. 2015. A Plasmodium phospholipase is involved in disruption of the liver stage parasitophorous vacuole membrane. PLoS Pathog 11:e1004760. 
1030

1031

1032

1033

1034

1035

1036

1037

1038

1039

1040

1041

1042

1043

1044

1045

1046

1047

1048

75. Pszenny V, Ehrenman K, Romano JD, Kennard A, Schultz A, Roos DS, Grigg ME, Carruthers VB, Coppens I. 2016. A Lipolytic Lecithin:Cholesterol Acyltransferase Secreted by Toxoplasma Facilitates Parasite Replication and Egress. J Biol Chem $291: 3725-3746$.

76. Daussy CF, Wodrich H. 2020. "Repair Me if You Can”: Membrane Damage, Response, and Control from the Viral Perspective. Cells 9:E2042.

77. Farr GA, Zhang L, Tattersall P. 2005. Parvoviral virions deploy a capsid-tethered lipolytic enzyme to breach the endosomal membrane during cell entry. Proc Natl Acad Sci U S A 102:17148-17153.

78. Staring J, von Castelmur E, Blomen VA, van den Hengel LG, Brockmann M, Baggen J, Thibaut HJ, Nieuwenhuis J, Janssen H, van Kuppeveld FJM, Perrakis A, Carette JE, Brummelkamp TR. 2017. PLA2G16 represents a switch between entry and clearance of Picornaviridae. Nature 541:412-416.

79. Radulovic S, Troyer JM, Beier MS, Lau AO, Azad AF. 1999. Identification and molecular analysis of the gene encoding Rickettsia typhi hemolysin. Infect Immun $67: 6104-6108$.

80. Voss OH, Gillespie JJ, Lehman SS, Rennoll SA, Beier-Sexton M, Rahman MS, Azad AF. 2020. Risk1, a Phosphatidylinositol 3-Kinase Effector, Promotes Rickettsia typhi Intracellular Survival. mBio 11:e00820-20. 
1049

1050

1051

1052

1053

1054

1055

1056

1057

1058

1059

1060

1061

1062

1063

1064

1065

1066

1067

1068

81. Cheng Y-L, Wu Y-W, Kuo C-F, Lu S-L, Liu F-T, Anderson R, Lin C-F, Liu Y-L, Wang W-Y, Chen Y-D, Zheng P-X, Wu J-J, Lin Y-S. 2017. Galectin-3 Inhibits Galectin-8/Parkin-Mediated Ubiquitination of Group A Streptococcus. mBio 8:e00899-17.

82. Engström P, Burke TP, Mitchell G, Ingabire N, Mark KG, Golovkine G, lavarone AT, Rape M, Cox JS, Welch MD. 2019. Evasion of autophagy mediated by Rickettsia surface protein OmpB is critical for virulence. Nat Microbiol 4:25382551.

83. Engström P, Burke TP, Tran CJ, lavarone AT, Welch MD. 2021. Lysine methylation shields an intracellular pathogen from ubiquitylation and autophagy. Sci Adv 7:eabg2517.

84. Saarikangas J, Zhao H, Lappalainen P. 2010. Regulation of the actin cytoskeletonplasma membrane interplay by phosphoinositides. Physiol Rev 90:259-289.

85. Senju Y, Kalimeri M, Koskela EV, Somerharju P, Zhao H, Vattulainen I, Lappalainen P. 2017. Mechanistic principles underlying regulation of the actin cytoskeleton by phosphoinositides. Proc Natl Acad Sci U S A 114:E8977-E8986.

86. Senju Y, Lappalainen P. 2019. Regulation of actin dynamics by PI(4,5)P2 in cell migration and endocytosis. Curr Opin Cell Biol 56:7-13.

87. Fukumatsu M, Ogawa M, Arakawa S, Suzuki M, Nakayama K, Shimizu S, Kim M, Mimuro H, Sasakawa C. 2012. Shigella targets epithelial tricellular junctions and 
1069

1070

1071

1072

1073

1074

1075

1076

1077

1078

1079

1080

1081

1082

1083

1084

1085

1086

1087

uses a noncanonical clathrin-dependent endocytic pathway to spread between cells. Cell Host Microbe 11:325-336.

88. Sanderlin AG, Vondrak C, Scricco AJ, Fedrigo I, Ahyong V, Lamason RL. 2019. RNAi screen reveals a role for PACSIN2 and caveolins during bacterial cell-to-cell spread. Mol Biol Cell 30:2124-2133.

89. Czuczman MA, Fattouh R, van Rijn JM, Canadien V, Osborne S, Muise AM, Kuchroo VK, Higgins DE, Brumell JH. 2014. Listeria monocytogenes exploits efferocytosis to promote cell-to-cell spread. Nature 509:230-234.

90. Dennis EA, Norris PC. 2015. Eicosanoid storm in infection and inflammation. Nat Rev Immunol, 2015/07/03 ed. 15:511-523.

91. Sheppe AEF, Edelmann MJ. 2021. Roles of Eicosanoids in Regulating Inflammation and Neutrophil Migration as an Innate Host Response to Bacterial Infections. Infect Immun 89:e0009521.

92. Takano T, Clish CB, Gronert K, Petasis N, Serhan CN. 1998. Neutrophil-mediated changes in vascular permeability are inhibited by topical application of aspirintriggered 15-epi-lipoxin A4 and novel lipoxin B4 stable analogues. J Clin Invest $101: 819-826$.

93. Liu Z-M, Tucker AM, Driskell LO, Wood DO. 2007. Mariner-based transposon mutagenesis of Rickettsia prowazekii. Appl Environ Microbiol 73:6644-6649. 
1088

1089

1090

1091

1092

1093

1094

1095

1096

1097

1098

1099

1100

1101

1102

1103

1104

1105

1106

94. Choe, Julie. 2015. The Rickettsia Late Motility Factor Sca2 Exhibits Species

Differences in its Actin Assembly Mechanism. University of California, Berkeley.

Proquest ID: Choe_berkeley_0028E_15819. Retrieved from

https://escholarship.org/uc/item/9wd7s7vn.

95. Solovyev V, Salamov A. 2011. Automatic Annotation of Microbial Genomes and Metagenomic Sequences. In Metagenomics and its applications in agriculture, biomedicine, and environmental studies (Ed. R.W. Li). Nova Science Publisher's, p.61-78.

96. Mitra A, Kesarwani AK, Pal D, Nagaraja V. 2011. WebGeSTer DB--a transcription terminator database. Nucleic Acids Res 39:D129-135.

97. Winger JA, Derbyshire ER, Lamers MH, Marletta MA, Kuriyan J. 2008. The crystal structure of the catalytic domain of a eukaryotic guanylate cyclase. BMC Struct Biol 8:42.

98. Jeng RL, Goley ED, D’Alessio JA, Chaga OY, Svitkina TM, Borisy GG, Heinzen RA, Welch MD. 2004. A Rickettsia WASP-like protein activates the Arp2/3 complex and mediates actin-based motility. Cell Microbiol 6:761-769.

99. Anacker RL, Mann RE, Gonzales C. 1987. Reactivity of monoclonal antibodies to Rickettsia rickettsii with spotted fever and typhus group rickettsiae. J Clin Microbiol 25:167-171. 
Figures
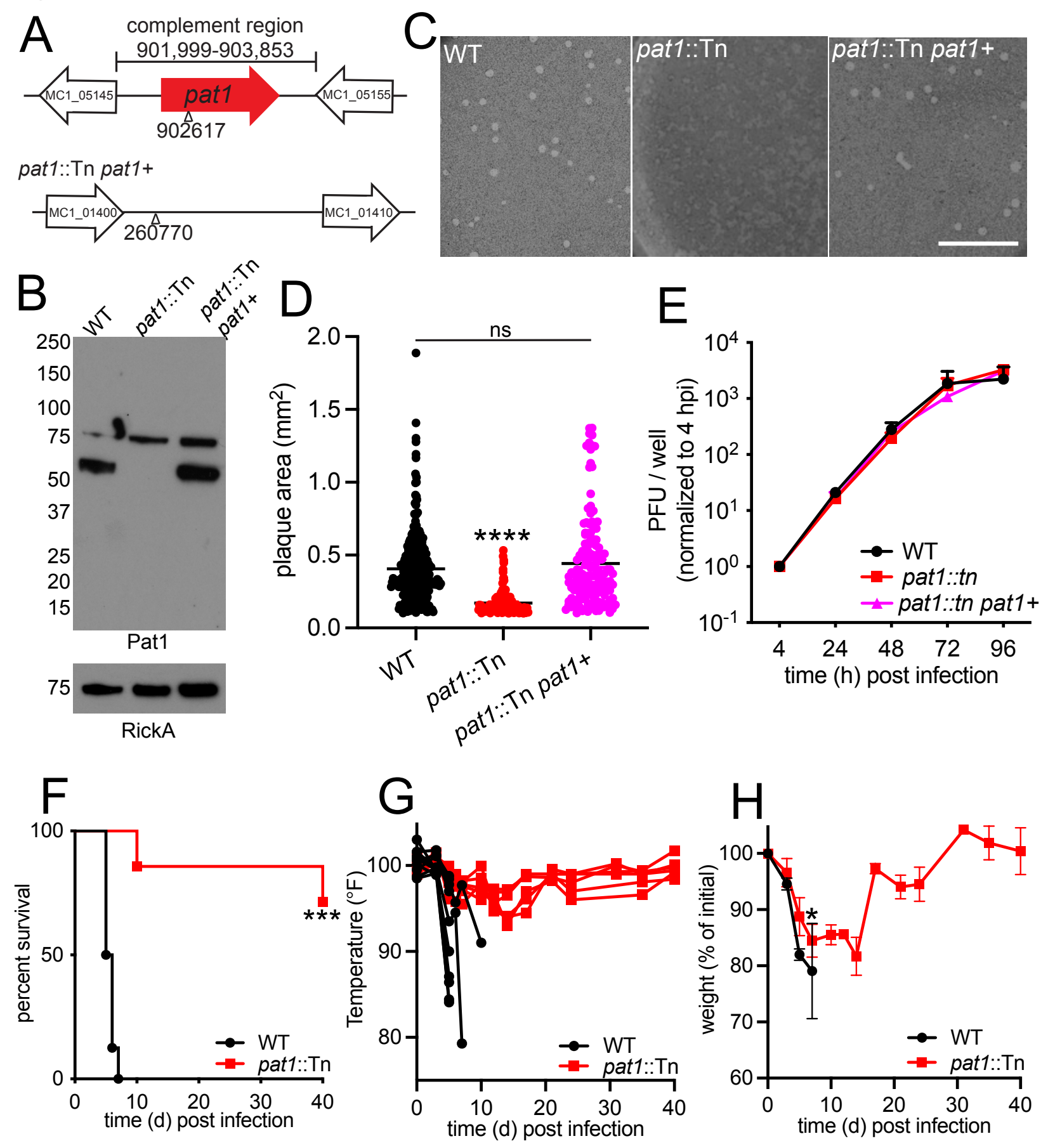

Fig. 1 Pat1 is important for infection of cells and in mice. (A) Genomic loci of pat1

1111 (top) and pat1 insertion site for complementation (bottom). Triangle represents

1112 transposon insertion sites, and nucleotide numbers indicate the position in the $R$.

1113 parkeri genome. Genes upstream and downstream are included to show intergenic 
1114 regions. (B) Western blot of purified R. parkeri strains, WT, pat1::Tn, and complemented

1115 strain (pat1::Tn pat1+), probed with anti-Pat1 antibody; probing with anti-RickA was

1116 used as a loading control. Pat1 has a predicted size of 55kD. Numbers on left are

1117 molecular weight in $\mathrm{kD}$. (C) Images of plaques stained with neutral red at $6 \mathrm{dpi}$. Scale

1118 bar $10 \mathrm{~mm}$. (D) Plaque areas in Vero cells infected with WT, pat1::Tn, and

1119 complemented strain ( $\mathrm{n}=2$ independent experiments; $50-80$ plaques per experiment).

1120 (E) Growth curve of WT, pat1::Tn, and complemented strain in HMECs ( $n=3$

1121 independent experiments). (F) Survival of Ifnar $1^{-/ /} ;$/fngr $1^{1 /-}$ mice infected intravenously

1122 (i.v.) with $5 \times 10^{6}$ WT or pat $1:: T n$ mutant ( $\mathrm{n}=8$ mice for WT, $\mathrm{n}=7$ mice for pat1::Tn, data

1123 represents 2 independent experiments). (G) Temperature changes over time in i.v.

1124 infection of Ifnar ${ }^{-/}$; Ifngr $1^{-/}$mice with $5 \times 10^{6}$ WT or pat $1:$ Tn mutant bacteria; graphs

1125 represent data from individual mice. $(\mathrm{H})$ Weight change over time expressed as percent

1126 change from initial weight in i.v. infection of Ifnar $1^{-/}$;fngr ${ }^{-/}$mice with $5 \times 10^{6} \mathrm{WT}$ or

1127 pat1::Tn mutant bacteria. Data in (D) and (E) are mean $\pm \mathrm{SEM} ;{ }^{* * * *} \mathrm{p}<0.0001$ relative to

1128 WT (one-way ANOVA), ns=not significant. Data in $(F)$ were analyzed using a log-rank

1129 (Mantel-Cox) test ${ }^{* * *} \mathrm{p}<0.001$. Data in $(\mathrm{H})$ were analyzed using a two-way ANOVA from 11300 to $7 \mathrm{dpi}$. 

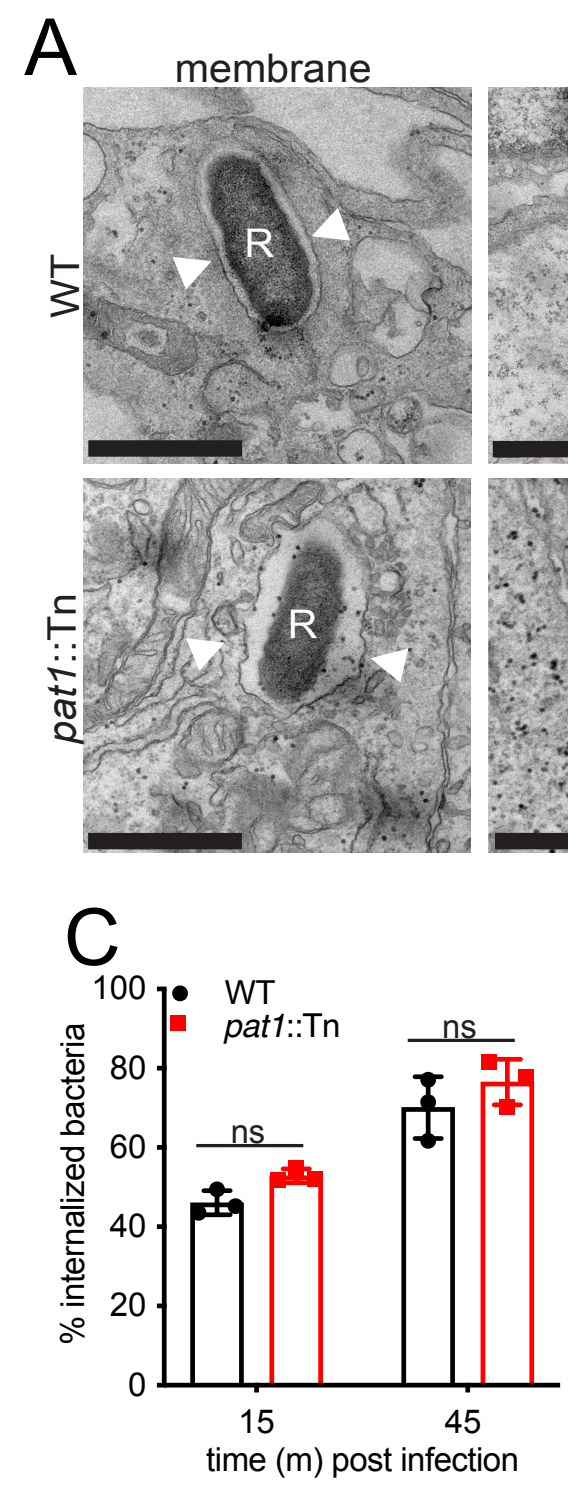

cytosol
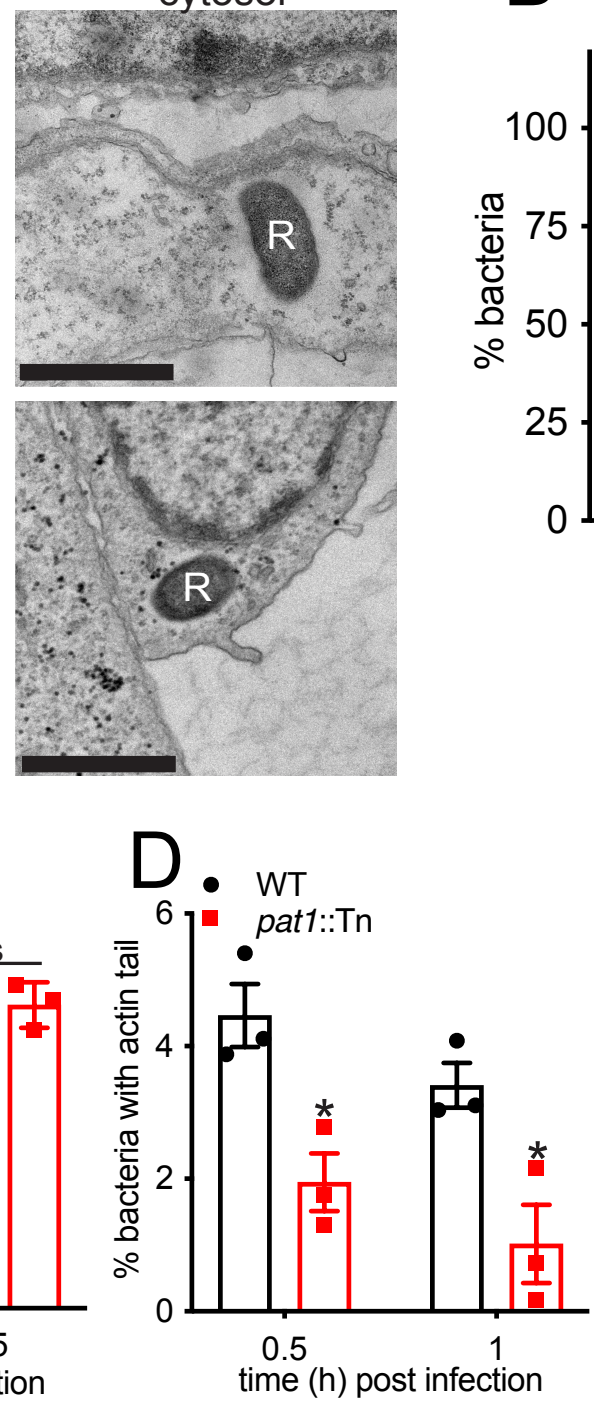

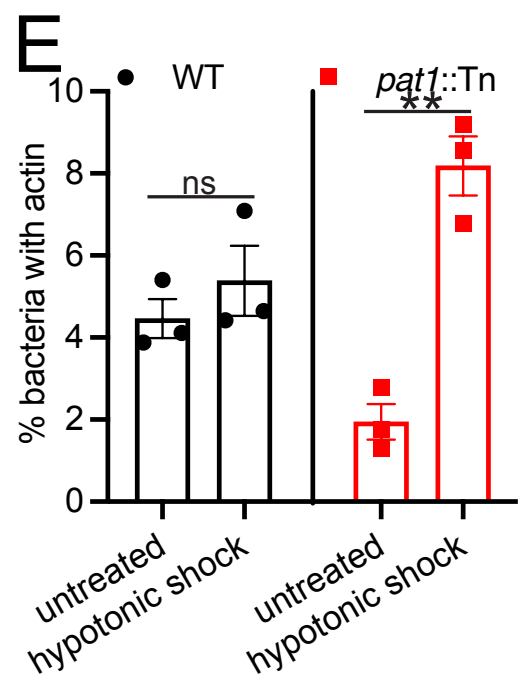

Fig. 2 Pat1 facilitates escape from single and double membrane compartments

following invasion. (A) TEM images of WT and pat1::Tn mutant bacteria in HMECs at

$11341 \mathrm{hpi}$. "R" indicates $R$. parkeri and arrowheads point to membrane surrounding the

1135 bacteria. Scale bar $1 \mu \mathrm{m}$. (B) Quantification of (A), percentage of single and double

1136 membrane-bound or cytosolic bacteria (WT=80 bacteria, pat1::Tn=88 bacteria, $\mathrm{n}=3$

1137 independent experiments). (C) Percent of bacteria internalized at $15 \mathrm{mpi}$ and $45 \mathrm{mpi}$ 
1138 (images not shown). (D) Percent of bacteria with actin tails at $30 \mathrm{mpi}$ and $1 \mathrm{hpi}$ (images

1139 not shown). (E) Percent of bacteria with actin in untreated cells or cells that have

1140 undergone hypotonic shock treatment to lyse vacuoles (images not shown). All data

1141 represents $n=3$ independent experiments. Data in $(B, C, D)$ are mean $\pm S E M$;

$1142{ }^{* * *} p<0.001^{* *} p<0.01{ }^{*} p<0.05$, ns=not significant relative to WT (unpaired t-test). Data in

$1143(E)$ are mean $\pm S E M ;{ }^{*} p<0.01$ relative to untreated (paired t-test). 

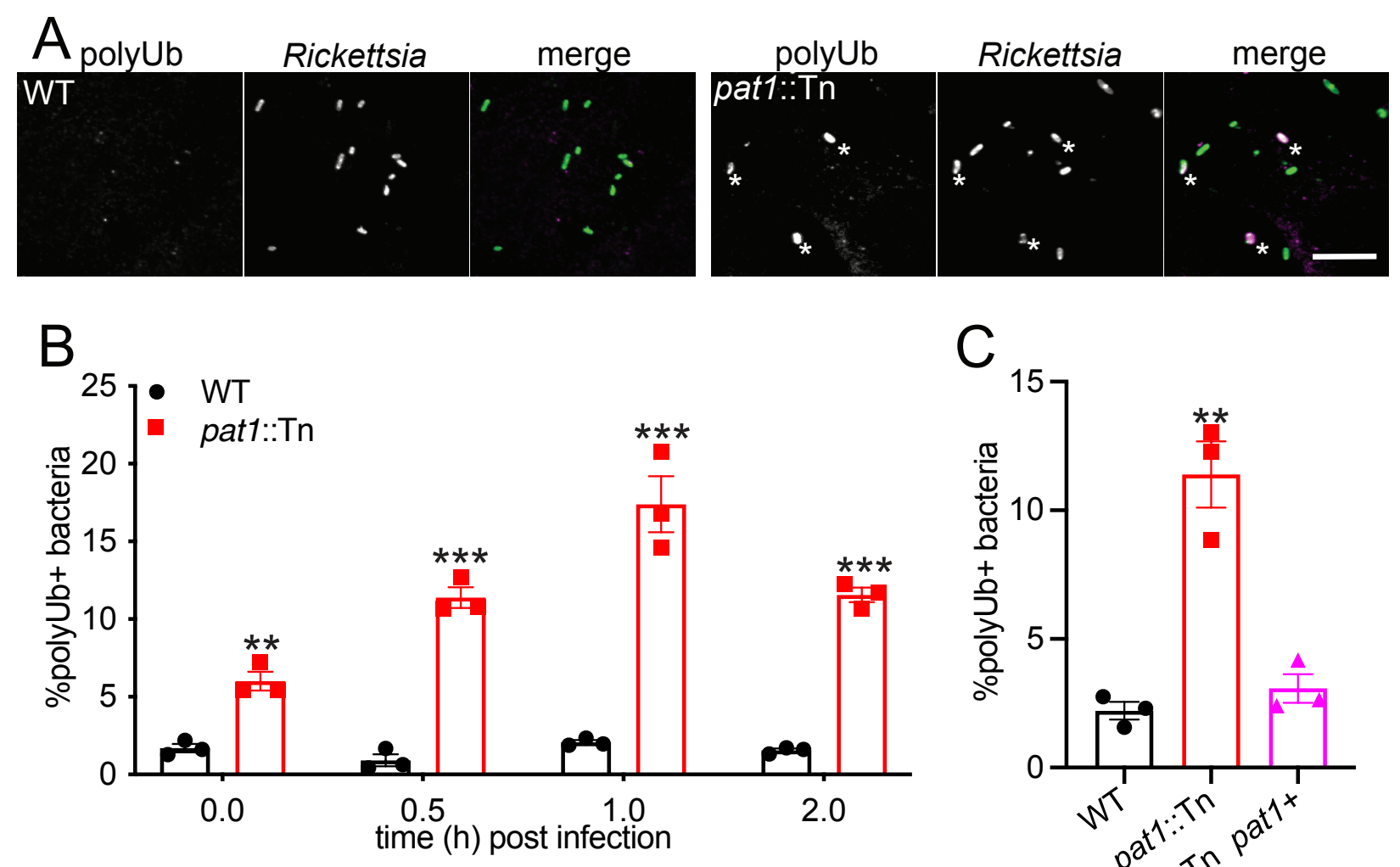

C

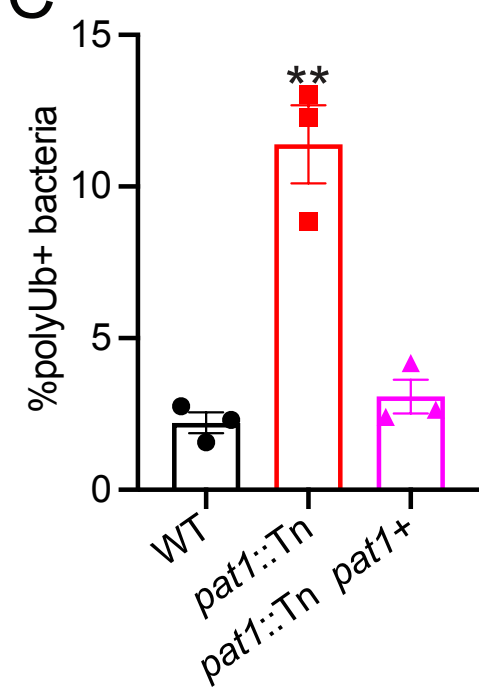

1145 Fig. 3 Pat1 contributes to avoidance of polyubiquitin recruitment. (A) Images of

1146 polyubiquitin (polyUb; magenta in merge) in HMECs infected with WT and pat1::Tn

1147 bacteria (green in merge) at $1 \mathrm{hpi}$. Asterisk denotes colocalization between bacterium

1148 and polyUb. Scale bar is $5 \mu \mathrm{m}$. (B) Quantification of (A), percentage of polyUb-positive

1149 bacteria at the indicated time points. (C) Percent of polyUb-positive bacteria in HMECs

1150 infected with WT, pat1::Tn, or complemented mutant (pat1::Tn pat1+) at 1 hpi. All data

1151 represent $n=3$ independent experiments. Data in $(B)$ are mean $\pm S E M ;{ }^{* * *} p<0.001$

$1152{ }^{* *} \mathrm{p}<0.01^{*} \mathrm{p}<0.05$ relative to WT (unpaired t-test). Data in (C) are mean $\pm \mathrm{SEM}$;

$1153^{* * *} \mathrm{p}<0.001^{* *} \mathrm{p}<0.01^{*} \mathrm{p}<0.05$ relative to WT (one-way ANOVA). 

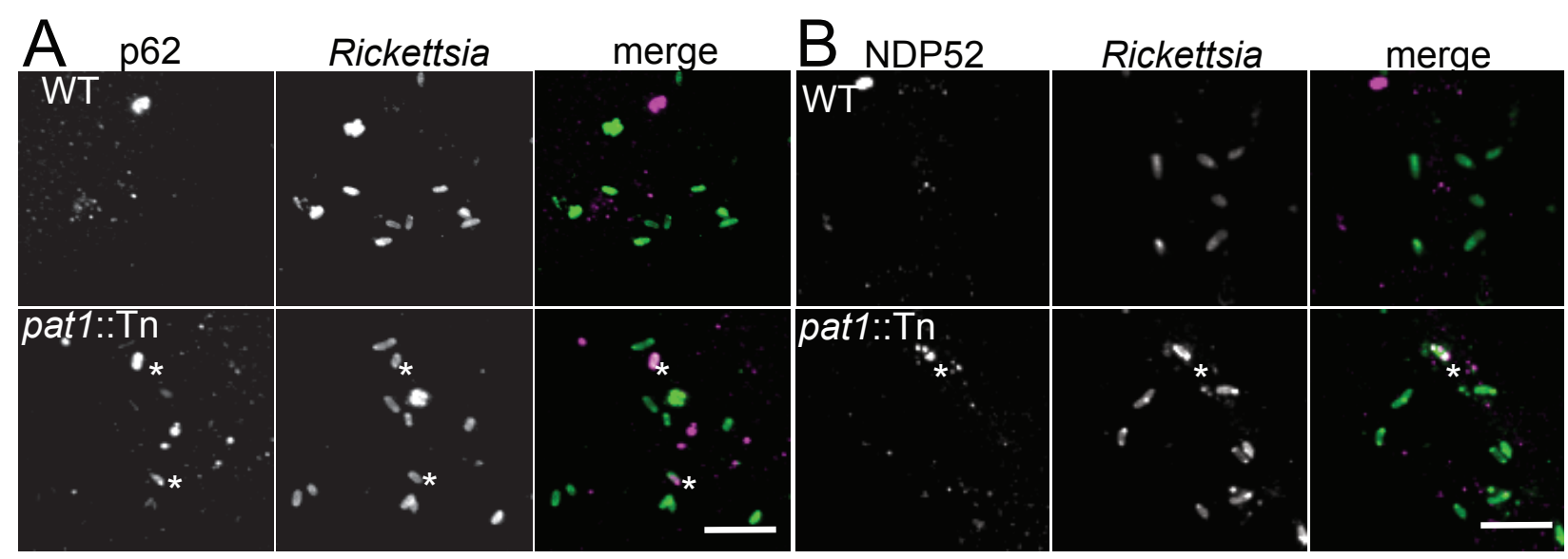

C

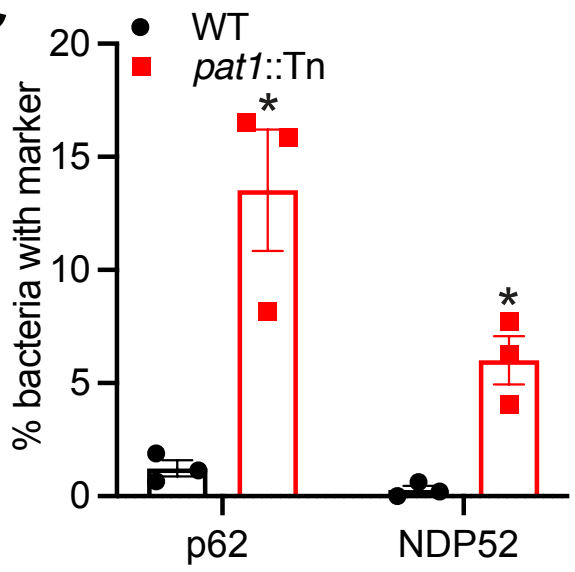

$\mathrm{D}$

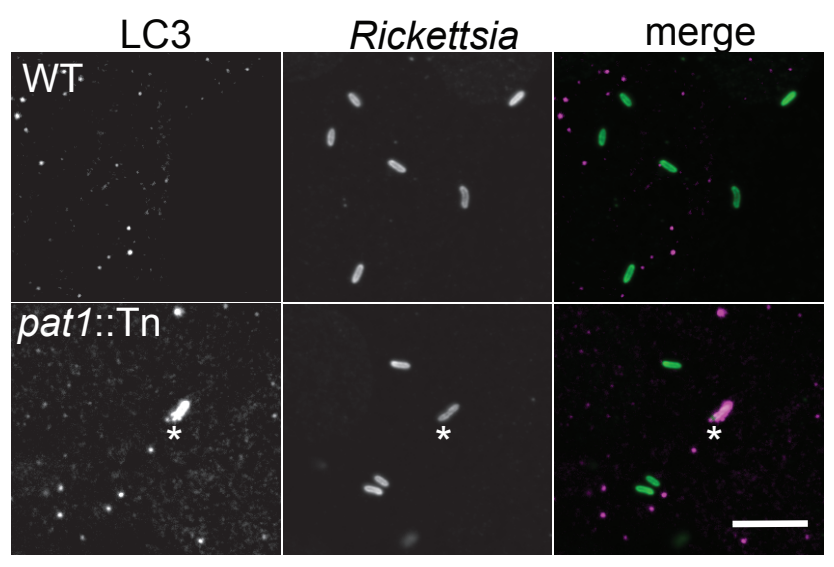

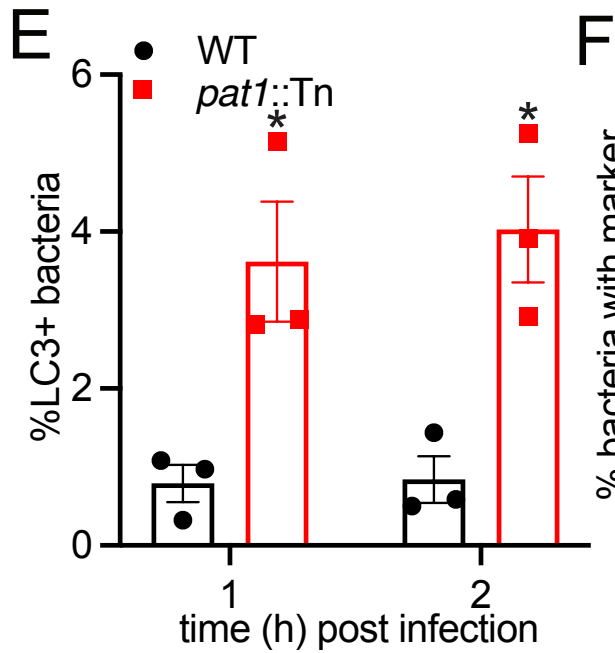

F $\quad$ - $\begin{array}{ll}\text { WT } \\ 25 & \text { pat1::Tn }\end{array}$

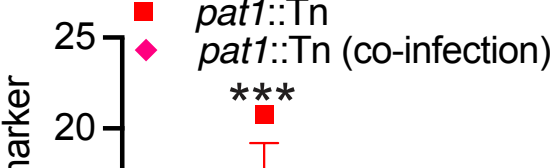
time (h) post infection

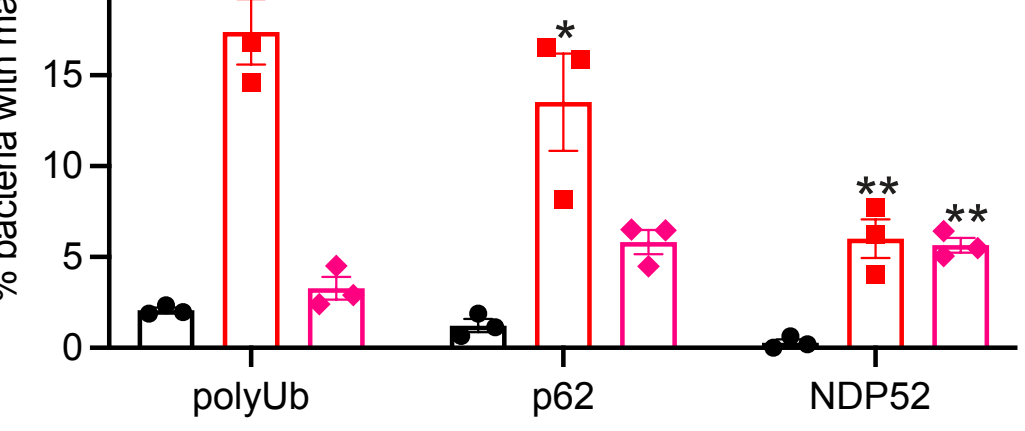

Fig. 4 Pat1 enables evasion of recognition by autophagy. Images of autophagy

1156 receptors (A) NDP52 (left; magenta in merge) and (B) p62 (right; magenta in merge) in

1157 WT and pat1::Tn (green in merge) infected HMECs. Asterisk denotes colocalization 
1158 between bacterium and p62 or NDP52. (C) Quantification of (A) and (B), percentage of

1159 bacteria staining for NDP52 or p62 at $1 \mathrm{hpi}$. (D) Images of LC3 (magenta) in HMECs

1160 infected with WT and pat1::Tn bacteria (green) at $1 \mathrm{hpi}$. Asterisk denotes colocalization

1161 between bacterium and LC3. (E) Quantification of percent bacteria staining for LC3 at 1

1162 hpi (images in (D)) and 2 hpi (images not shown). (F) Percentage colocalization of

1163 bacteria with polyUb, NDP52, and p62 in HMECs infected with WT, pat1::Tn mutant, or

1164 co-infected with WT and pat1::Tn mutant. For co-infections, quantification is for pat1::Tn

1165 bacteria only. All data represents $n=3$ independent experiments. Data in $(C, E)$ are

1166 mean \pm SEM; ${ }^{* *} \mathrm{p}<0.001^{* *} \mathrm{p}<0.01^{*} \mathrm{p}<0.05$ relative to WT (unpaired t-test). Data in $(\mathrm{F})$

1167 are mean $\pm \mathrm{SEM} ;{ }^{* * *} \mathrm{p}<0.001{ }^{* *} \mathrm{p}<0.01{ }^{*} \mathrm{p}<0.05$ relative to WT (one-way ANOVA). Scale

1168 bars in (A, B, D) are $5 \mu \mathrm{m}$. 

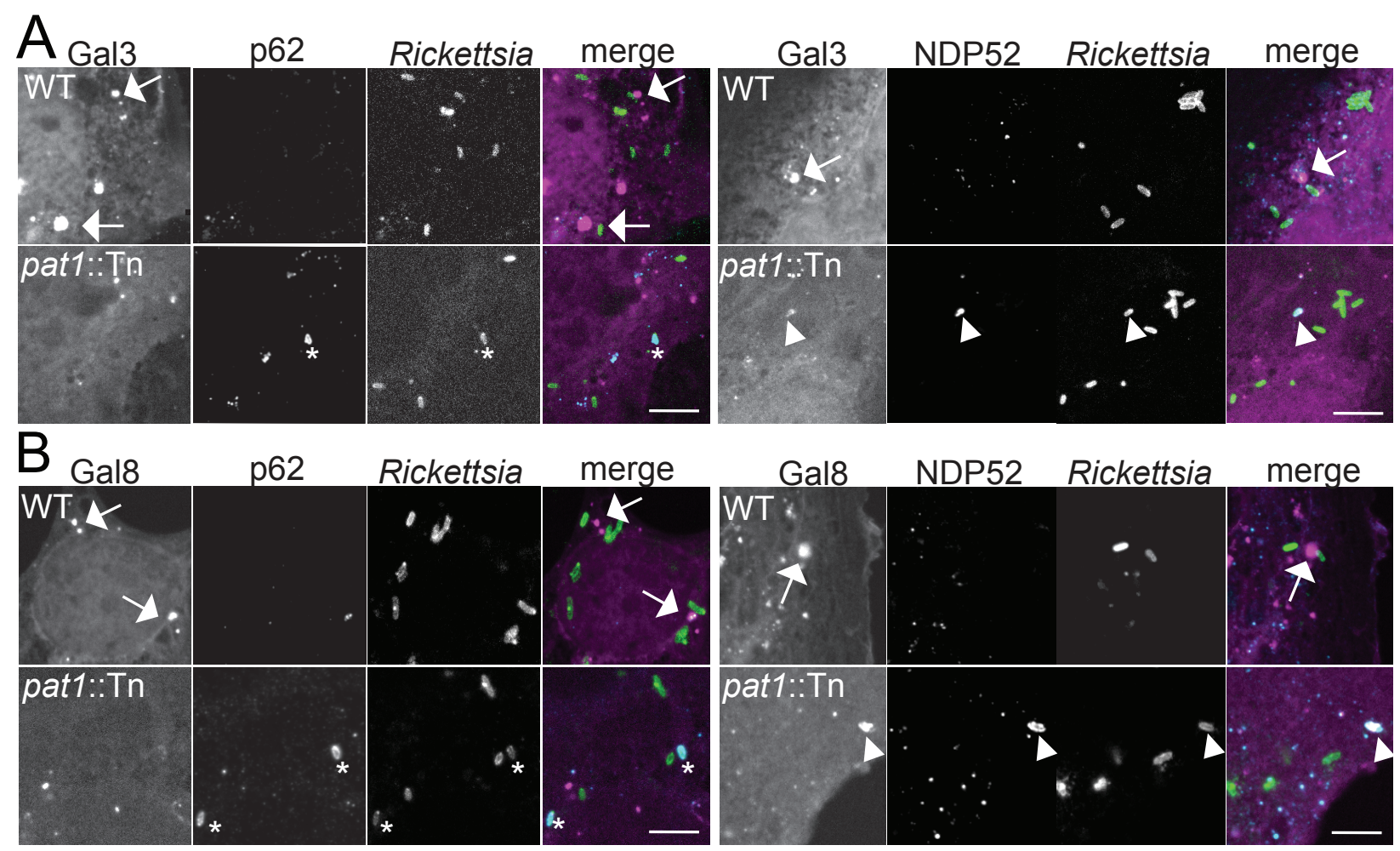

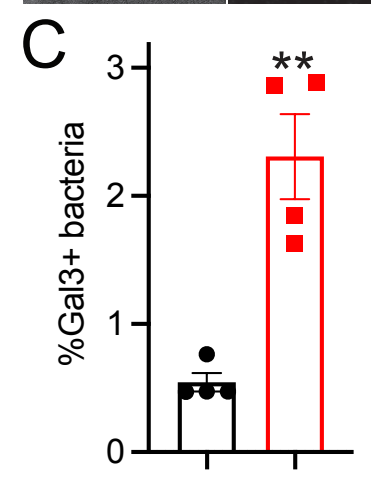

$\mathrm{F}$

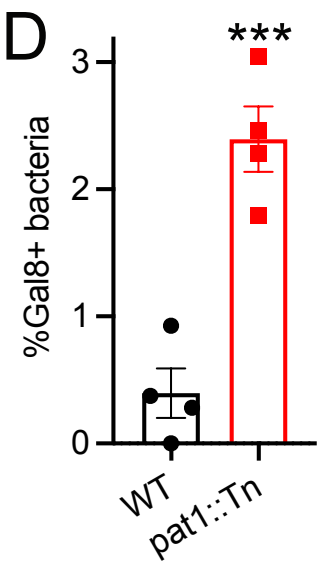

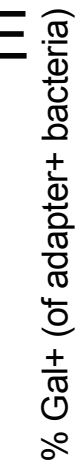

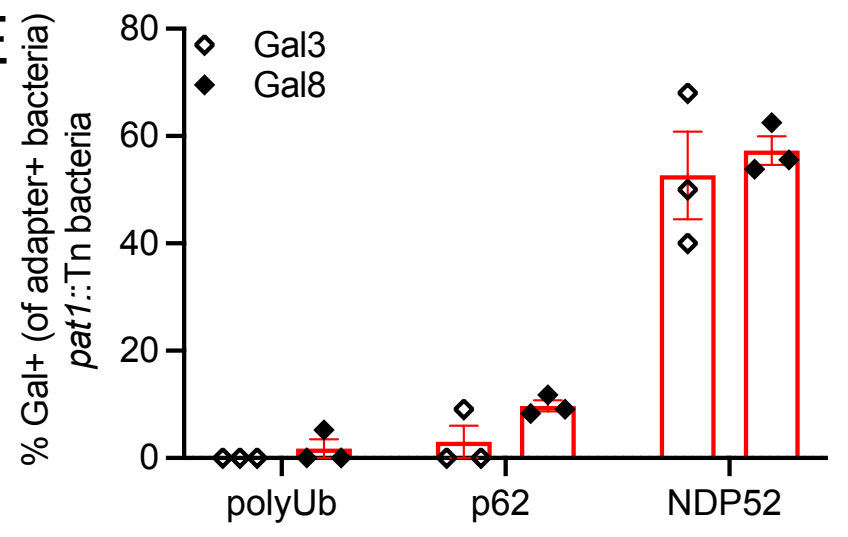

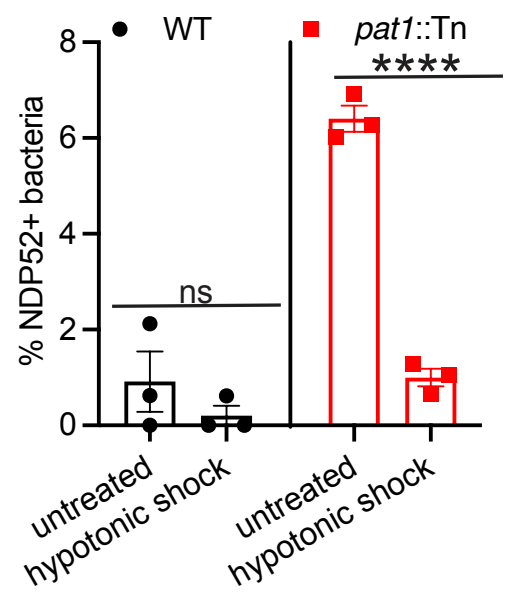


Fig. 5 Pat1 is important for avoiding bacterial association with damaged

1171 membranes. (A) Images of Gal3-mCherry (magenta in merge) and autophagy

1172 receptors p62 (left; cyan in merge) and NDP52 (right; cyan in merge) in HMECs infected

1173 with WT or pat1::Tn bacteria (green in merge) at $1 \mathrm{hpi}$. Arrows indicate large Gal3

1174 positive clusters near bacteria, asterisk indicates bacteria that are p62 positive and Gal3

1175 negative, arrowheads indicate colocalization between NDP52, Gal3, and bacteria. (B)

1176 Images of Gal8-mCherry (magenta in merge) and autophagy receptors p62 (left; cyan in

1177 merge) and NDP52 (right; cyan in merge) in HMECs infected with WT or pat1::Tn

1178 bacteria (green in merge) at $1 \mathrm{hpi}$. Arrows indicate large Gal8 positive clusters near

1179 bacteria, asterisk indicates bacteria that are p62 positive and Gal8 negative,

1180 arrowheads indicate colocalization between NDP52, Gal8, and bacteria. Scale bar for

1181 (A) is $5 \mu \mathrm{m}$ and (B) is $3 \mu \mathrm{m}$. (C) Quantification of (A), percentage of bacteria positive for

1182 Gal3 (n=4). (D) Quantification of (B), percentage of bacteria positive for Gal8 $(n=4)$. (E)

1183 Quantification of (A) and (B), percent of polyUb, p62, or NDP52 positive pat1::Tn

1184 bacteria that are also positive for Gal3 (open diamond) or Gal8 (filled diamond) ( $n=3$ for

1185 all markers). (F) Percent of bacteria positive for NDP52 in untreated cells or cells that

1186 undergo hypotonic lysis of vesicles $(n=3)$. Data in (C) and (D) represent $n=4$

1187 independent experiments and data in (E) and (F) represent $n=3$ independent

1188 experiments. Data in (C), (D) are mean \pm SEM; ${ }^{* \star} p<0.001{ }^{* *} p<0.01$ relative to WT

1189 (unpaired t-test). Data in $(F)$ are mean $\pm S E M ;{ }^{* *} p<0.01$ relative to untreated (paired $t-$ 1190 test). 


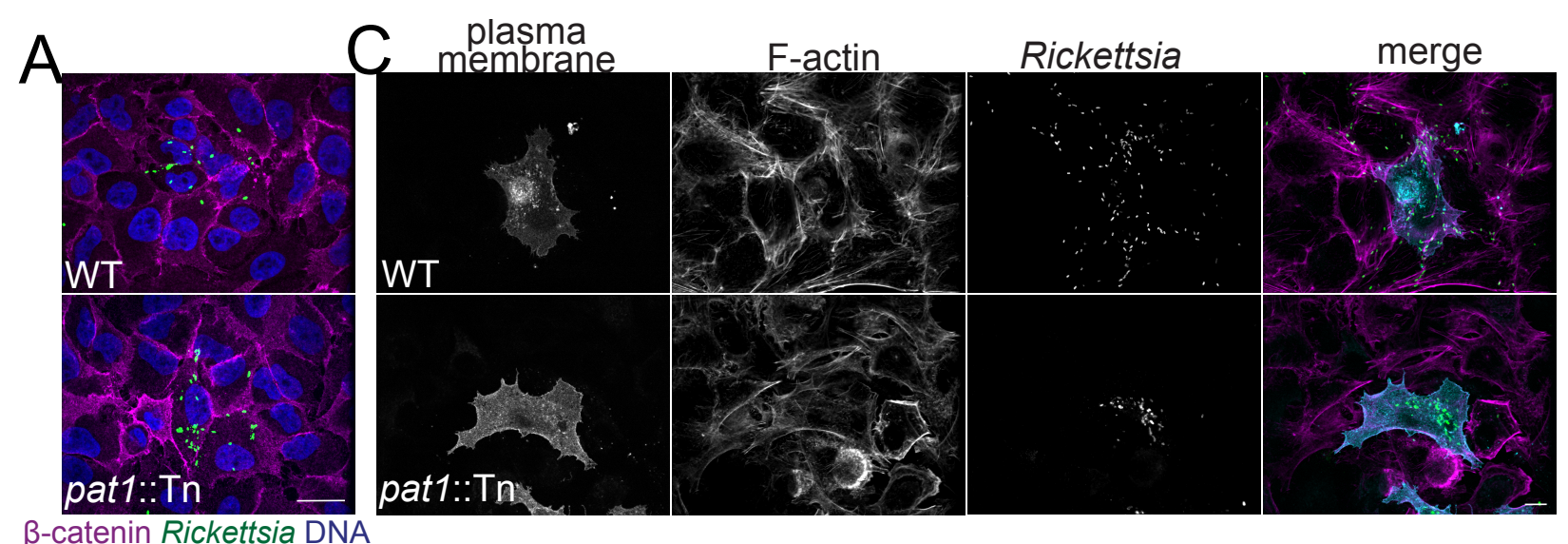

$\beta$-catenin Rickettsia DNA
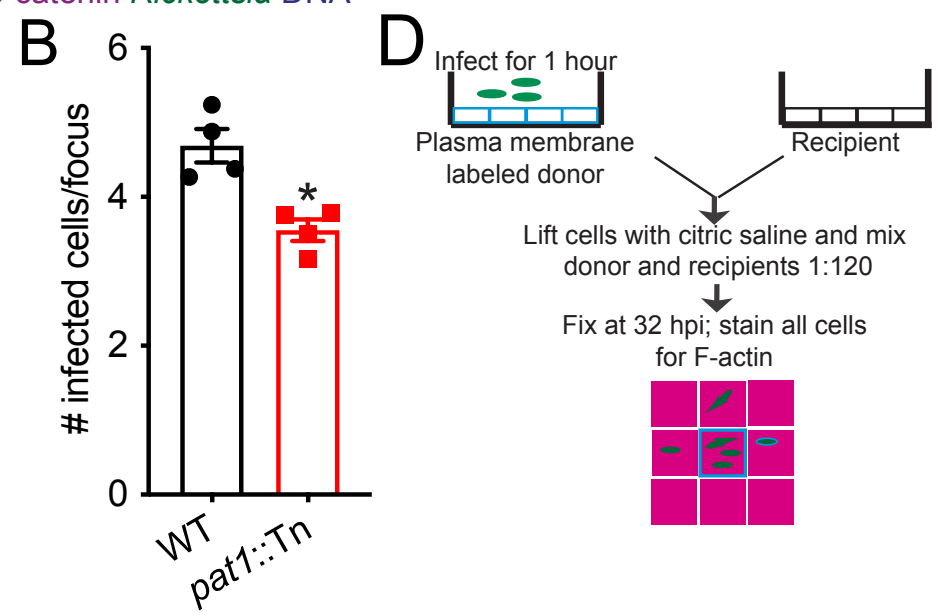
donor and recipients 1:120 Fix at 32 hpi; stain all cells for F-actin
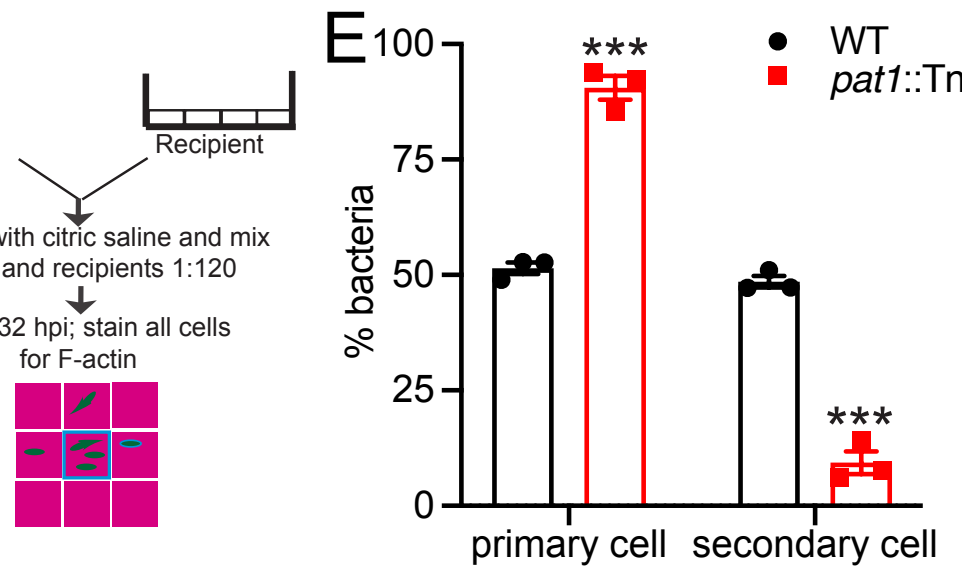

F
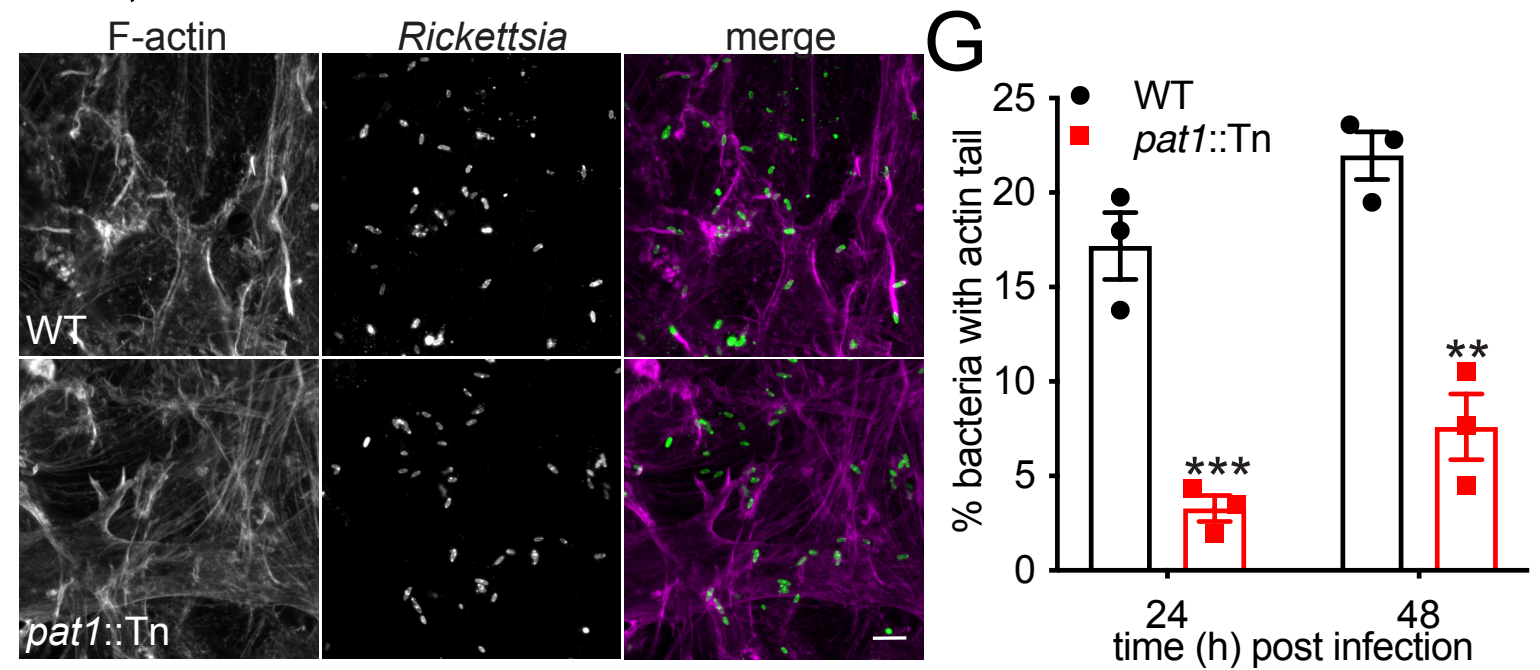

Fig. 6 Pat1 is important for cell-cell spread and facilitates actin-based motility. (A)

1193 Images of infectious foci formed by WT or pat1::Tn mutant in A549 cells at $28 \mathrm{hpi}$

1194 (magenta, $\beta$-catenin; green, bacteria; blue, nuclei). Scale bar is $10 \mu \mathrm{m}$. (B)

1195 Quantification of $(A)$, number of infected cells per focus $(n=4) .(C)$ Images of mixed cell 
1196 assay depicted in (D) showing plasma membrane (A549-TRTF; cyan in merge), F-actin

1197 (magenta in merge), and bacteria (green in merge), adapted from (67). Scale bar is 10

$1198 \mu \mathrm{m}$. (E) Percent bacteria in primary and secondary cells quantified from (C) $(n=3) .(F)$

1199 Images of actin tails (F-actin; magenta in merge) and bacteria (green in merge) in

1200 HMECs at $24 \mathrm{hpi}$. (G) Percent of bacteria with actin tails at $24 \mathrm{hpi} \mathrm{(from} \mathrm{(F)} \mathrm{and} 48 \mathrm{hpi}$

1201 in HMECs (images not shown) $(n=3)$. Scale bar is $5 \mu$ m. Data in (B) represents $n=4$

1202 independent experiments and data in $(E)$ and $(G)$ represent $n=3$ independent

1203 experiments. All data are mean \pm SEM; ${ }^{* *} p<0.001{ }^{* *} p<0.01{ }^{*} p<0.05$ relative to WT

1204 (unpaired t-test). 
A
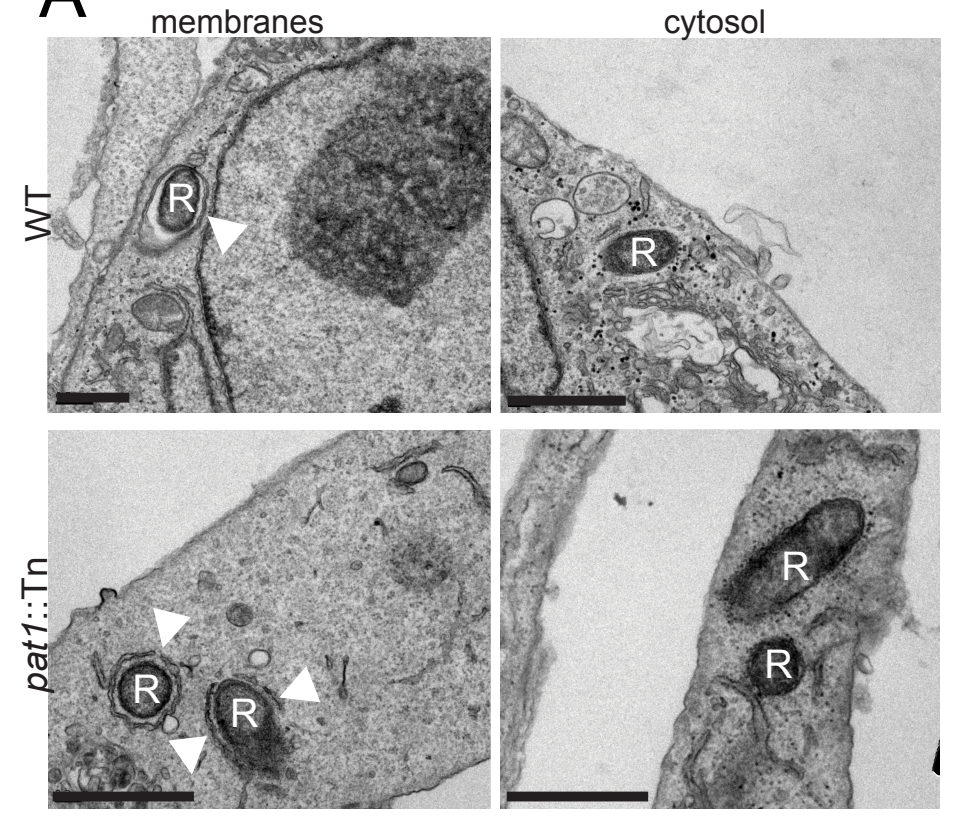

C

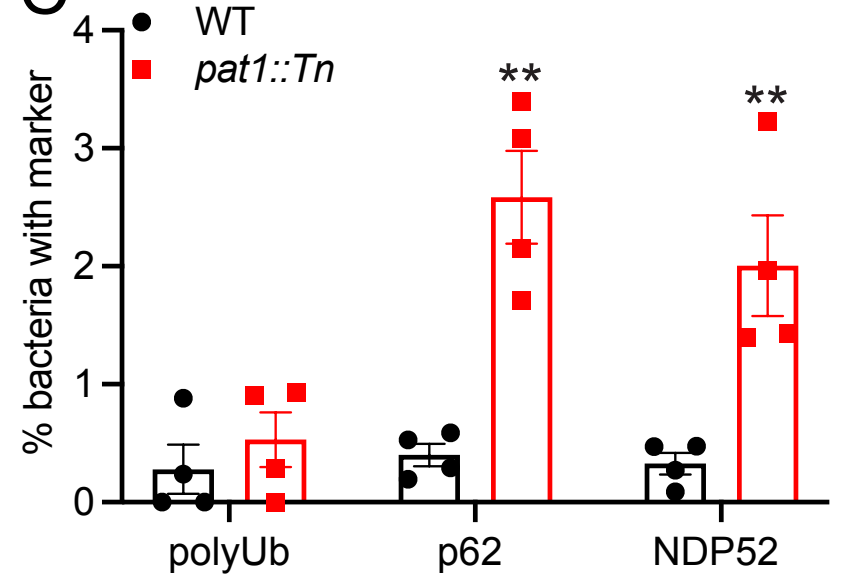

B

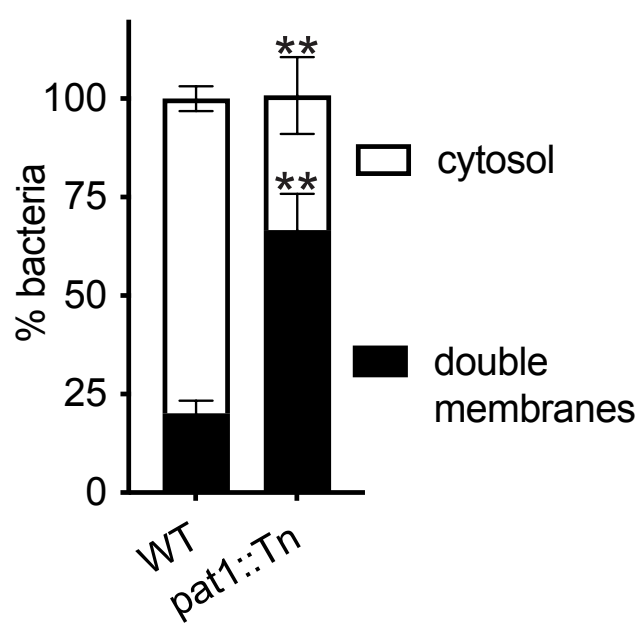

$\mathrm{D}$

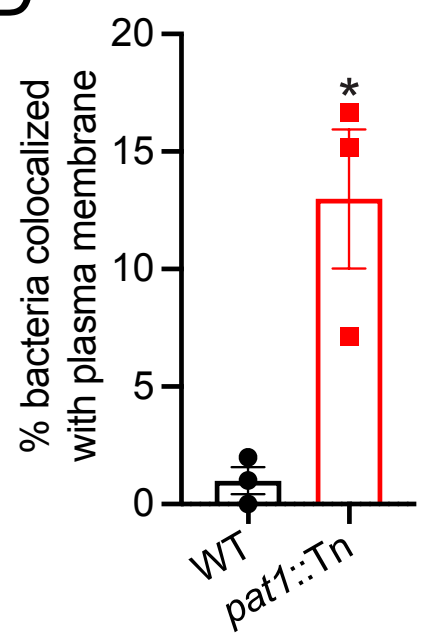

Fig. 7 Pat1 is important for escape from the secondary vacuole. (A) TEM images of WT and pat1::Tn mutant bacteria in HMECs at 48 hpi. "R" indicates R. parkeri and

1208 arrowheads point membranes surrounding the bacteria. Scale bar $1 \mu \mathrm{m}$. (B) Percentage

1209 of bacteria in double membrane compartments or in the cytosol (WT $n=120$ bacteria,

1210 pat1::tn $\mathrm{n}=112$ bacteria, $\mathrm{n}=3$ independent experiments). (C) Percentage of bacteria in

1211 the secondary cell that colocalize with the plasma membrane from the primary cell, in 
bioRxiv preprint doi: https://doi.org/10.1101/2021.10.21.465009; this version posted October 21, 2021. The copyright holder for this preprint

(which was not certified by peer review) is the author/funder, who has granted bioRxiv a license to display the preprint in perpetuity. It is made available under aCC-BY-NC-ND 4.0 International license.

1212 mixed cell assays from Figure 5C at $32 \mathrm{hpi} \mathrm{(} \mathrm{n}=3$ independent experiments). (D)

1213 Percentage of WT and pat1::Tn mutant bacteria colocalizing with polyUb, p62, and

1214 NDP52 (all $n=4$ independent experiments) at $48 \mathrm{hpi}$ in HMECs. All data are mean \pm

1215 SEM; ${ }^{* *} p<0.01{ }^{*} p<0.05$ relative to WT (unpaired t-test). 